\title{
DEVELOPMENT AND ASSESSMENT OF DISCRIMINATION EXCERCISES FOR FACULTY CALIBRATION IN PRECLINICAL OPERATIVE DENTISTRY
}

\author{
SUMITHA NAZAR AHMED
}

A thesis submitted to the Faculty of The University of North Carolina at Chapel Hill in partial fulfillment of the requirements for the degree of Master of Science in the Department of Operative Dentistry at the School of Dentistry

\section{Chapel Hill}

2014

Approved by:

Lee W. Boushell

John Sturdevant

Rebecca S. Wilder

Vicki Kowlowitz 
(C) 2014

SUMITHA NAZAR AHMED

ALL RIGHTS RESERVED 


\begin{abstract}
Sumitha Nazar Ahmed: Development and Assessment of Discrimination Exercises for Faculty calibration in Preclinical Operative Dentistry

(Under the direction of Lee Boushell)
\end{abstract}

The purpose of this research was to develop and assess methods for faculty calibration in a preclinical operative dentistry course, to evaluate intra- and interexaminer agreement based on the information provided during calibration sessions, and to evaluate intra- and interexaminer reliability 6 months after initial calibration. The average intraexaminer agreement among the course faculty was $74(+/-5) \%$. The overall interexaminer reliability improved after calibration. The use of an instrument (UNC 15 periodontal probe) was introduced, for objective measurement of a component. Visual discrimination exercises were developed and tested for their ability to1) initially aid in increased faculty calibration while assessing the Class II preparation and 2) provide sustained calibration among the same faculty over a period of approximately 3 months. The results showed that, the objective use of an instrument (UNC 15 periodontal probe) and the use of discrimination exercises increased interexaminer reliability. 
To my husband Yashin Ahmed, my children Adi and Ian, your love and support made this dream come true.

To my parents Naziruddin and Jameela Nazar who taught me that success come from following one's heart

To Rameez Nazar, Sunitha, Imthiaz Kadeer and my nephew Omi, thank you for being there for me 


\section{ACKNOWLEDGEMENTS}

To my Thesis Committee members, Dr. Lee Boushell, Dr. John Sturdevant, Ms. Rebecca Wilder and Dr. Vicki Kowlowitz, I am grateful for your time, encouragement and guidance

Dr. Terry Donovan, Dr. Harald Heymann, Dr. Andre Ritter and Dr. Edward Swift, it has been an honor to be your student

To the staff of the Department of Operative Dentistry, Shannon Tate, Dayna

McNaught, Jamie Desoto, Rosanna Arrington, Barbara Walton and Cynthia Lambert. Thank you for always being there, ready to help.

I would like to thank Dr. Rick Walter and Dr. Leinfelder for taking the time to participate in my thesis project. Dr. May, Dr. Eidson and Dr. Zandona, thank you for making me feel like a part of the Operative family.

Dr. Ceib Phillips and Ms. Debbie Price, I thank you for your time and guidance with the statistical analysis. Dr. Wilder thank you for being so patient with me and all the help you have given me over the years.

Alex and Silvia you have been the best classmates. I will never forget these three years of sharing accomplishments, success and failures. You will be in my heart forever

To all the Operative residents who made this journey memorable, Ayesha, Roopsie, Upoma, Villi, Clay, Tan, Mohammad, Anmar and Taiseer. Thank you!

A special thank you to Dr. James Parker for all your help and advice 


\section{TABLE OF CONTENTS}

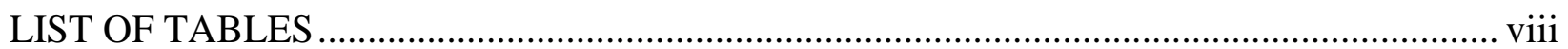

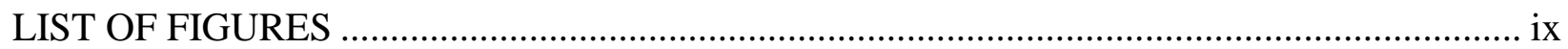

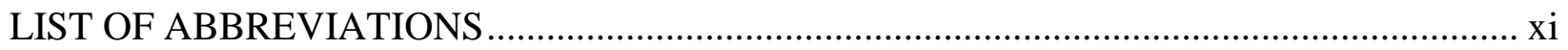

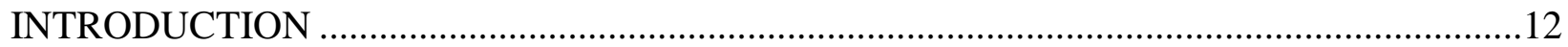

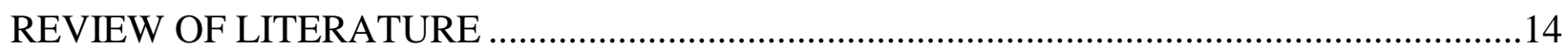

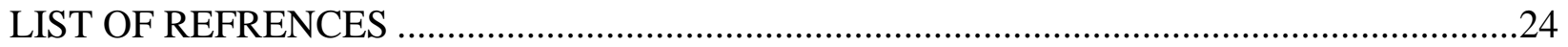

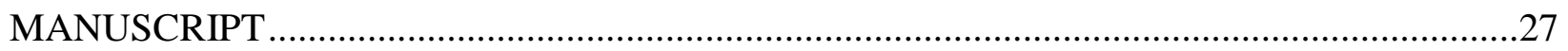

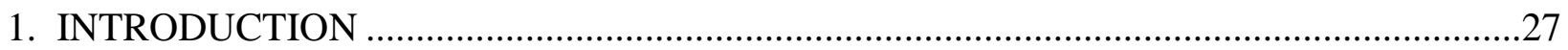

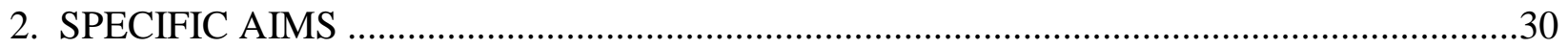

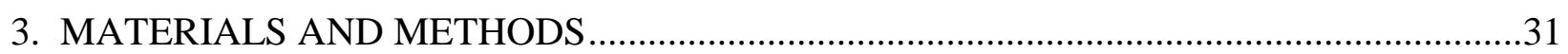

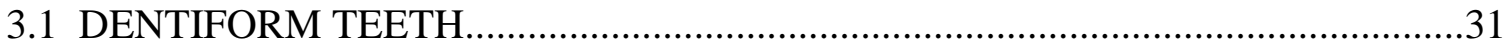

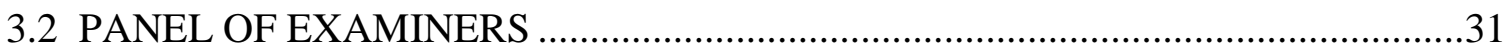

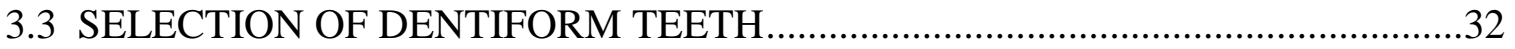

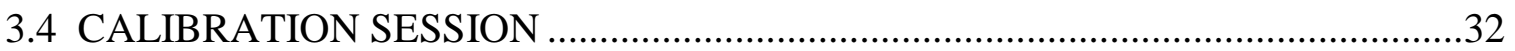

3.5 DISCRIMINATION EXERCISE RATIONALE ………..........................................

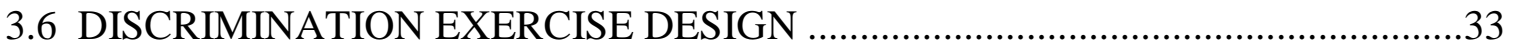

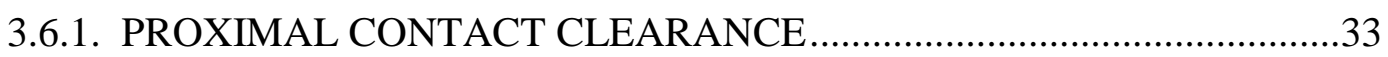

3.6.2. RETENTION GROOVE PLACEMENT ……………………....................34 


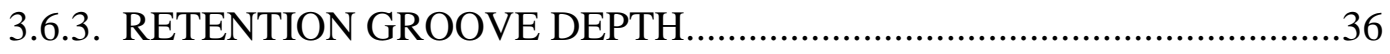

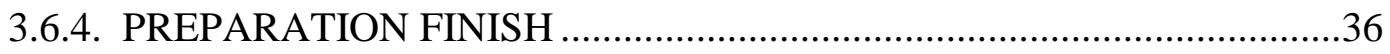

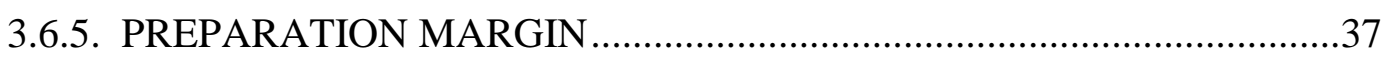

3.7 REVIEW OF ASSESSMENT RUBRIC ……………...............................................38

3.8 TIMING OF PHASE I AND PHASE II ASSESSMENT ……………………….......39

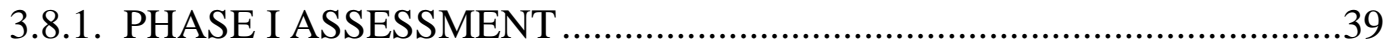

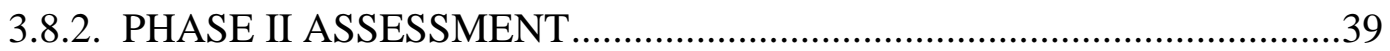

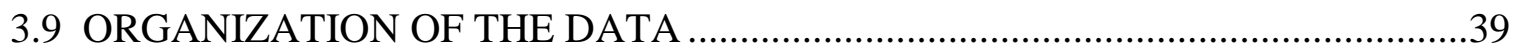

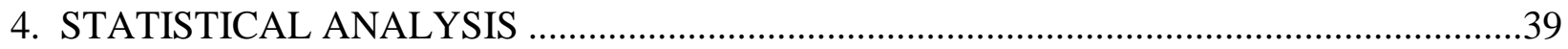

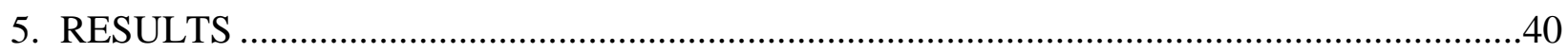

5.1 INTEREXAMINER RELIABILITY - PHASE I ………………………………....40

5.2 INTRAEXAMINER RELIABILITY - PILOT STUDY TO PHASE I ......................41

5.3 INTEREXAMINER RELIABILITY - PHASE II ...................................................41

5.4 INTRAEXAMINER RELIABILITY - PHASE II.................................................42

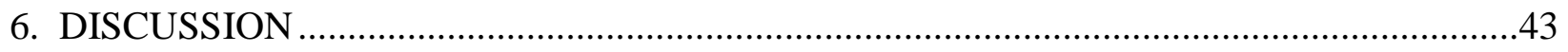

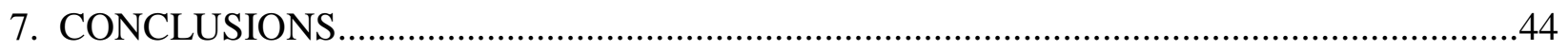

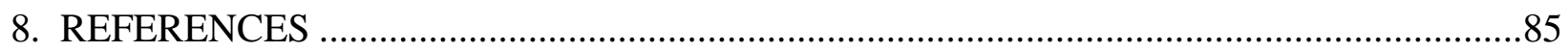




\section{LIST OF TABLES}

TABLE 1 - Class II Amalgam Procedure Performance Assessment Rubric Used For the Pilot Study, Phase I and Phase II.

TABLE 2 - Average percent agreement (mean +/- sd) and 95\% CI for assessment of components of Class II cavity preparation during the Pilot study

TABLE 3 - Class II amalgam procedure assessment rubric that was used to define the level of student performance and associated point values for each component

TABLE 4 - Average percent agreement (mean $+/$ - sd) and 95\% CI for assessment of components of Class II cavity preparation during Phase I

TABLE 5 - Average percentage intra examiner agreement for each examiner when comparing the results from Pilot Study to Phase I

TABLE 6 - The level of intraexaminer variation (\%) for all 13 components of Class II cavity preparation for each examiner when comparing Pilot study to Phase I

TABLE 7 - Average percent agreement (mean $+/$ - sd) and 95\% CI for assessment of components of Class II cavity preparation during Phase II

TABLE 8 - Average percentage intraexaminer agreement for each examiner when comparing the results from Pilot Study to Phase II

TABLE 9 - Average percentage intraexaminer agreement for each examiner when comparing the results from Phase I to Phase II

TABLE 10 - The level of intraexaminer variation (\%) for all 13

components of Class II cavity preparation for each examiner when comparing the Pilot Study to Phase II.

TABLE 11 - The level of intraexaminer variation (\%) for all 13 components of Class II cavity preparation for each examiner when comparing Phase I to Phase II 


\section{LIST OF FIGURES}

FIGURE 1 - Average percentage agreement among examiners after assessment of 13 procedural components of Class II cavity preparations, identified in the pilot study.

FIGURE 2.1- The mean diameter of the UNC 15 probe at the $4-5 \mathrm{~mm}$ mark was $0.5+/-0.02$ and $0.75+/-0.02$ at the $11-12 \mathrm{~mm}$ mark. The measurements were made using the Image $\mathrm{J} @$ software

FIGURE 2.2- 3D model used to demonstrate clinically acceptable example of proximal contact clearance.

FIGURE 2.3 - 3D model used to demonstrate clinically unacceptable example of proximal contact clearance.

FIGURE 3.1- 3D model demonstrating clinically unacceptable retention groove placement in the enamel facial wall of a preparation with ideal axial wall depth .55

FIGURE 3.2- 3D model demonstrating clinically unacceptable retention groove placement at the DEJ of the facial wall of a preparation with ideal axial wall depth.

FIGURE 3.3 - 3D model demonstrating clinically acceptable retention groove placement $\sim 0.2 \mathrm{~mm}$ internal to the DEJ such that it is partially in the dentin facial wall and partially in the adjacent axial wall of a preparation with ideal axial wall depth.

FIGURES 3.4- 3D model demonstrating clinically unacceptable retention groove placement in the axial wall of a preparation with ideal axial wall depth.....

FIGURES 3.5- 3D model demonstrating clinically unacceptable retention groove placement in the gingival wall of a preparation with ideal axial wall depth

FIGURES 3.6- 3D model demonstrating clinically acceptable retention groove placement $\sim 0.2 \mathrm{~mm}$ internal to the DEJ in the facial dentin wall of a preparation with deep axial wall depth

FIGURES 3.7- 3D model demonstrating clinically unacceptable retention groove placement in the line angle of the facial and axial walls of a preparation with deep axial wall depth

FIGURES $4.1 \& 4.2$ - 3D model demonstrating clinically acceptable preparation finish of smooth walls and gentle transitions 
FIGURES $4.3 \& 4.4$ - 3D model demonstrating clinically unacceptable preparation finish of smooth walls and abrupt transitions

FIGURES 4.5 \& 4.6 - 3D model demonstrating clinically unacceptable preparation finish of rough walls and gentle transitions.

FIGURES $4.7 \& 4.8$ - 3D model demonstrating clinically unacceptable preparation finish of rough walls and abrupt transitions

FIGURE 5.1- Image of the 3D model with a superimposed protractor that demonstrates clinically unacceptable preparation wall orientation of $<80^{\circ}$ 66

FIGURE 5.2- Image of the 3D model with a superimposed protractor that demonstrates clinically unacceptable preparation wall orientation of $>100^{0}$

FIGURE 5.3- Image of the 3D model with a superimposed protractor that demonstrates clinically acceptable preparation wall orientation of approximately $90^{0} \cdots \ldots \ldots \ldots . . . .68$

FIGURE 6- Average percentage agreement after assessment of 13 procedural components of Class II cavity preparations among examiners at Pilot Study and Phase I

FIGURE 7 - The component 'Enamel Present' had the lowest intraexaminer variation from Pilot Study to Phase I

FIGURE 8 - The component 'Proximal Contact Clearance' had the highest intraexaminer variation from Pilot Study to Phase I.

FIGURE 9- Average percentage agreement among examiners after assessment of 13 procedural components of Class II cavity preparations, identified in the post

FIGURE 10 - The component 'Isthmus Width' had the lowest intraexaminer variation from Pilot Study: Phase I: Phase II

FIGURE 11 - The component 'Proximal Contact Clearance' had the highest intraexaminer variation from Pilot Study: Phase I: Phase II. 


\section{LIST OF ABBREVIATIONS}

$\begin{array}{ll}\text { 3D } & \text { 3 Dimensional } \\ \text { CI } & \text { Confidence Interval } \\ \text { DEJ } & \text { Dentino-enamel Junction } \\ \text { EM } & \text { Electromagnetic } \\ \text { ICDAS } & \text { International Caries Detection and Assessment System } \\ \text { IRB } & \text { Institutional Review Board } \\ \text { MOD } & \text { Mesial Occlusal Distal } \\ \text { SD } & \text { Standard Deviation } \\ \text { UNC } & \text { University of North Carolina at Chapel Hill } \\ \text { US } & \text { The United States of America } \\ & \text { Glance and Grade } \\ & \end{array}$




\section{Introduction}

Dental students undergo rigorous pre-clinical training in preparation for entrance into the clinical setting. Dental faculty utilizes simulated clinical settings in pre-clinical courses for the purpose of developing and assessing dental students' knowledge and skills pre-requisite for patient care. Conservative Operative Dentistry (DENT112) is an example of a pre-clinical operative dentistry taught at the UNC School of Dentistry.

In the didactic session of the pre-clinical operative course the students learn the theory behind different designs of cavity preparations. During the hands-on (or laboratory) session of the course, they use this theoretical information to develop the hand skill necessary for preparing and restoring cavities on dentiform teeth that are mounted in manikins. As part of the preclinical course, they come in contact with multiple faculty who grade their work. Learning Theory suggests that it is very important that the information given to the students remain consistent from one instructor to the other in order to avoid any confusion among the students.

As future dentists, dental students are expected to make clinical judgments based on their education. In any educational setting, students rely on the faculty to provide consistent formative and summative feedback. They also rely on the faculty to provide reinforcement and enhancement of concepts that they learn in their dental curriculum. Learning is optimal when multiple faculty 
are consistent with each other as they communicate concepts to their students.

Active steps must be taken to increase the levels of consistency, or agreement or calibration among faculty. Poor consistency among faculty may lead to confusion and frustration among the students. 


\section{Review of Literature}

Evaluation methods can be broadly classified into subjective evaluation and objective evaluation. While the word subjective can change from person to person, objective means a fixed reality. Subjectivity associated with grading student performance can lead to confusion and stress among the students. Fuller states that, in an evaluation system guided by subjectivity, it is often difficult for the faculty to "defend" his/her score to the student's satisfaction or his/her own. ${ }^{1}$

According to Jenkins et al, the problems with faculty consistency may lead students to perceive that evaluation methods are somewhat arbitrary. They suggested that this concept can undermine the learning process and produce a negative effect on undergraduate's confidence and performance. ${ }^{2}$ Their findings support the idea that consistency in the feedback provided to the students helps to improve their performance and also avoids ambiguity associated with grading procedures. Mackenzie recommends 'maximizing diagnostic feedback' (using objective evaluation methods), for the purpose of student learning. ${ }^{3}$ This can only be accomplished by establishing a system that makes use of objective evaluation methods.

The consistency or degree of agreement between faculty members, performing the task of grading samples of student's work, is known as examiner reliability. ${ }^{4}$ Examiner reliability can be divided into intraexaminer reliability 
and interexaminer reliability. Intraexaminer reliability describes the consistency of a single examiner in grading the same sample on multiple occasions. ${ }^{4}$ Interexaminer reliability measures the degree of agreement among the examiners when they evaluate the performance of the same group of students on the same task. ${ }^{5}$ Studies in the field of faculty calibration have shown that establishing agreement among faculty members is not an easy task. This can be due to the inconsistent grading methods, differing rating scales, individual teaching philosophy and so on.

Clinical performance can be judged in terms of its 3 possible outcomes. Performance that: 1) is clinically acceptable, 2) needs improvement and 3) is clinically unacceptable. American dental schools have historically assessed performance in pre-clinical simulations of the clinical environment by using 3 methods: 1) Glance and Grade (GG), 2) Checklist (CL) and 3) Checklist with Specific Criteria (CLSC). The Glance and Grade method utilizes a subjective global assessment of the student performance without specific evaluation of each component of the skill. of a skill. ${ }^{6}$ The Checklist and Checklist with Specific Criteria methods seek to utilize a more analytical form of evaluation where each component of the entire performance is evaluated separately on a written checklist. The Checklist with Specific Criteria method also defines specific levels of performance of each component.

Houpt and Kress suggests that global assessment can be used for the purpose of certification, i.e., in a situation where the student performance needs to be evaluated as 'satisfactory' or 'unsatisfactory'. ${ }^{7}$ Mackenzie refers to global 
assessment as a 'product approach' and points out that it should be supplemented with other forms of evaluation. He argues that looking only at the measure of the end-product, without analyzing the factors that contribute to the variations in quality of the product, results in wasteful repetition of the evaluation process. ${ }^{3}$

Both global and analytical approaches have been tested to determine the level of intra- and interexaminer reliability. Goepferd and Kerber ${ }^{8}$ developed and tested the efficiency of an analytical system for evaluating class II cavity preparation on primary teeth. The intent of the analytical system was to decrease the subjectivity of clinical evaluation and to introduce objective measures in order to increase examiner reliability. This system was then compared with the traditional glance and grade method to determine degree of intra- and interexaminer reliability with both methods. The study found that the overall interexaminer reliability improved with the analytical system; however the findings were not tested for statistical significance.

Additional research comparing GG, CL and CLSC methods was accomplished at the University of North Carolina in 1983. The intra- and interexaminer reliability in preclinical pedodontic grading was evaluated. It was concluded that no method yielded superior intra- or interexaminer reliability. ${ }^{9}$

While some tried to increase intra and interexaminer reliability through different evaluation methods (GG vs CL vs CLSC), others have tried to gain superior intra- and interexaminer reliability through altering the nature of the rating scale within the various methods. Houpt and Kress compared 3 different 
rating scales: a two-point scale with two specified points, a five-point scale with end points specified and five-point scale with all end points defined. The findings of the study demonstrated that when criteria were defined specifically, examiners tended to be more accurate in their judgments. However, the use of a two-point rating scale was found to have more interexaminer agreement than the use of a five-point rating scale even though a five-point scale may be more beneficial for instructional purposes. ${ }^{7}$ Similar results by Hinkelman and Long showed slightly more interexaminer agreement in a two-point evaluation system (pass-fail) than a three-point scaling system ('no improvement necessary', 'clinically acceptable' and 'clinically unacceptable and uncorrectable'). However, the authors suggest that the three-point evaluation system was more useful for ranking according to ability. ${ }^{10}$

Although the results of these studies indicate that a two-point scale leads to greater examiner reliability, they highlight that it gives little to no instructional advantage in teaching and identifying components of a student's performance. In response to concerns about reliability and instructional quality, Deranleau et $\mathrm{l}^{11}$ conducted a study that investigated if the increase in intra- and interexaminer reliability gained from two-point scoring justified its use over the more instructionally advantageous three-point scoring. Porcelain jacket crown wax-ups and Class II MO wax-ups were assessed by 5 faculty members. All five examiners evaluated each project four times with a time interval of one week between grading sessions. The examiners were also asked about their preference regarding the grading system used and why. The results were similar to the 
Hinkelman and Long study who found increased interexaminer reliability in their collapsed two-point scoring system over three-point scale. The examiners who liked the two-option scoring were those with less experience. They disliked the range of competency assessment options and the levels assigned to some criteria. Those who preferred the three-option scoring method reported it allowed them to recognize superior work and, at the same time, avoid unrealistic expectations of perfection.

Research in the field of faculty calibration has also sought to analyze specific criteria, used in assessment methods, in terms of clarity of the verbiage. Studies that have carefully defined checkpoints, designed to decrease ambiguity, have obtained fairly high agreement among the examiners. ${ }^{12}$ As defined by Mackenzie et al, eliminating problems with the evaluation process includes, but are not limited to, items such as unstandardized aids to evaluate, incomplete operational definitions, discrepancies in visual acuity and inadequacy in verbal definitions. They concluded that the impact of these problems can be reduced by using checklists with definitions that describe how to make observations and how to categorize the observations with minimal inference or subjective bias. ${ }^{13}$

Sharaf et al, has suggested that the goal of educators should be to design a method of assessment that is both objective and reliable so as to reduce friction between students and faculty over the issue of grading. ${ }^{14}$ In an attempt to make the evaluation process more objective, Schiff et al designed a device called the "pulpal floor measuring instrument" to measure the profile of preparations, including depth, smoothness, and flatness of the pulpal floor. The 
authors reported significant improvement in operator consistency using this instrument. ${ }^{15}$ Cardoso et al used the Kavo PrepAssistant ${ }^{\circledR}$ to objectively evaluate student tooth preparations. The machine was used to compare an ideal tooth preparation by the faculty member against a preparation completed by a student. Both the preparations were digitally scanned and a data sheet containing preparation analysis and feedback was then processed which was given to the student. The authors found the use of the machine in its full potential by the preclinical department to be very labor intensive. Even with a greater guarantee of objective evaluation, the machine was not able to assess all the components of the tooth preparation, leaving $30 \%$ of the evaluation to be completed by the faculty. ${ }^{16}$

In the last two decades there have been an increasing number of studies on computer assisted learning and computer assisted simulation systems. ${ }^{17-19}$ DentSim ${ }^{\circledR}$ is one such system that has been gaining popularity among the dental schools in the nation. In addition to teaching operative dentistry preparation techniques, DentSim is also used to teach crown preparations and endodontic access cavities. The impact of DentSim on dental education has been studied extensively. ${ }^{20,21}$ Welk et al found that training with DentSim helped in early identification of students who needed more time to acquire the required skills. These students could be helped so as to avoid falling behind in the curriculum. They concluded that the time needed for training students to prepare specific cavities correctly in a conventional lab could be reduced so that the preparation tests of the operative dentistry course could be scheduled earlier than usual. ${ }^{22}$ 
Such devices help to ensure that the student receives an objective evaluation of their work in addition to consistent feedback. It should be noted that these systems currently cannot be used to provide formative and summative feedback for student performance of dental restorations.

In the absence of such devices the course director relies on the preclinical course faculty to provide consistent summative and formative feedback. Attempts to increase faculty consistency through improved communication of specific performance criteria, rating scales, and/or training have met with inconsistent results. ${ }^{23}$ One study found that faculty meetings designed to resolve inconsistencies did not result in increased calibration. ${ }^{24}$

Natkin and Guild reported a statistically significant increase in interexaminer reliability after the training sessions. Each session consisted of the examination of ten randomly selected student projects followed by discussion of the criteria established for those projects. ${ }^{25}$ A literature review by Patridge and Mast found that studies on faculty training yielded inconsistent results. ${ }^{26}$ Sometimes, the inconsistency and lack of fair grading is due to the absence of clear guidelines on how the examiners should evaluate clinical performances. ${ }^{27}$

Jenkins et al found that the level of pass-fail differences seemed to be unrelated to the experience of the examiner, with even the senior examiner recording differences of $17 \% .^{2}$ Lilley et al found similar results in their study with interexaminer variability fairly constant at $30-50 \%$ between 3 grading sessions, despite consultation among each other. However, they found high 
intraexaminer reliability particularly for the most experienced examiner. ${ }^{28}$ Philip Feil recommends the use of two examiners grading independently but working in association with one another to develop a bipartisan approach, which will theoretically facilitate a more uniform method of assessment by reducing the effect of individual bias. ${ }^{29}$

Scruggs et al conducted a pilot study to investigate the use of specific criteria and faculty calibration on the reliability of inexperienced examiners on dental sealant evaluations. The objectives of the study were to identify differences in calibrated and non-calibrated examiners. The examiners were calibrated by an expert and a non-expert to assess reliability among the study participants. They used an analytical, criteria based evaluation system. The results showed that the calibrated group had a higher reliability than the noncalibrated group. One important finding of the study was that the group calibrated by the expert actually decreased in interexaminer reliability after training. Based on these results, they concluded that the method used for calibrating examiners may be of more importance than the experience of the calibrator when planning a training session. ${ }^{30}$

Haj-Ali and Feil conducted a study of interexaminer reliability associated with a three-point rating scale assessment of Class II amalgam preparations over short and long term periods. They evaluated the immediate effects of calibration on interexaminer reliability as compared with a gold standard and determined if the effects could be sustained over a ten-week period. The examiners graded the samples at three different occasions: prior to calibration training, immediately 
following training, and ten weeks later. They concluded that, with training, interexaminer reliability with a gold standard can be improved and such improvement is reasonably resistant to deterioration after ten weeks. ${ }^{23}$

Salvendy et al, in their article from 1973, commented that "A dental student can acquire his skills most effectively when he is provided with and evaluated on objective and qualitative criteria measures". ${ }^{31}$ The criterion oriented method, by definition, reduces the subjectivity associated with grading. If the description of the criteria leaves no room for subjective interpretation, then it only enhances the communication between the student and the examiner.

Review of salient literature to date lends support to the notion that assessment methods that utilize CLSC afford the best possibility of achieving reasonable levels of faculty calibration. However, use of CLSC alone does not ensure calibration among course faculty. Methods of communicating the meaning and application of each criterion must be identified. Incorporation of standardized measurement instruments where ever possible becomes essential. The Department of Operative Dentistry at the University of North Carolina uses CLSC to support the teaching of principles inherent to the disciplines of operative dentistry. The current research studied the level of calibration among faculty in a pre-clinical operative dentistry course by identifying the level of inter- and intraexaminer reliability while assessing each of 13 components of a Class II cavity preparation for amalgam. Preparation components that revealed low interexaminer reliability were identified. An instrument for objective component measurement as well as visual discrimination exercises were 
developed and tested for their ability to1) initially aid in increased faculty calibration while assessing the Class II preparation and 2) provide sustained calibration among the same faculty over a period of approximately 3 months. 


\section{REFERENCES}

1. Fuller JL. The effects of training and criterion models on interjudge reliability. Journal of dental education. Apr 1972;36(4):19-22.

2. Jenkins SM, Dummer PM, Gilmour AS, Edmunds DH, Hicks R, Ash P. Evaluating undergraduate preclinical operative skill; use of a glance and grade marking system. Journal of dentistry. Nov 1998;26(8):679-684.

3. Mackenzie RS. Defining clinical competence in terms of quality, quantity, and need for performance criteria. Journal of dental education. Sep 1973;37(9):37-44.

4. Dhuru VB, Rypel TS, Johnston WM. Criterion-oriented grading system for preclinical operative dentistry laboratory course. Journal of dental education. Sep 1978;42(9):528531.

5. Brown G, Manogue M, Martin M. The validity and reliability of an OSCE in dentistry. European journal of dental education : official journal of the Association for Dental Education in Europe. Aug 1999;3(3):117-125.

6. Vanek HG. Objective evaluation of dental student technic products. Journal of dental education. Mar 1969;33(1):140-144.

7. Houpt MI, Kress G. Accuracy of measurement of clinical performance in dentistry. Journal of dental education. Jul 1973;37(7):34-46.

8. Goepferd SJ, Kerber PE. A comparison of two methods for evaluating primary class II cavity preparations. Journal of dental education. Sep 1980;44(9):537-542.

9. Vann WF, Machen JB, Hounshell PB. Effects of criteria and checklists on reliability in preclinical evaluation. Journal of dental education. Oct 1983;47(10):671-675.

10. Hinkelman KW, Long NK. Method for decreasing subjective evaluation in preclinical restorative dentistry. Journal of dental education. Sep 1973;37(9):13-18.

11. Deranleau NJ, Feiker JH, Beck M. Effect of percentage cut-off scores and scale point variation on preclinical project evaluation. Journal of dental education. Oct 1983;47(10):650-655.

12. Ryge G, Snyder M. Evaluating the clinical quality of restorations. Journal of the American Dental Association. Aug 1973;87(2):369-377.

13. Mackenzie RS, Antonson DE, Weldy PL, Welsch BB, Simpson WJ. Analysis of disagreement in the evaluation of clinical products. Journal of dental education. May 1982;46(5):284-289. 
14. Sharaf AA, AbdelAziz AM, El Meligy OA. Intra- and inter-examiner variability in evaluating preclinical pediatric dentistry operative procedures. Journal of dental education. Apr 2007;71(4):540-544.

15. Schiff AJ, Salvendy G, Root CM, Ferguson GW, Cunningham PR. Objective evaluation of quality in cavity preparations. Journal of dental education. Feb 1975;39(2):92-96.

16. Cardoso JA, Barbosa C, Fernandes S, Silva CL, Pinho A. Reducing subjectivity in the evaluation of pre-clinical dental preparations for fixed prosthodontics using the Kavo PrepAssistant. European journal of dental education : official journal of the Association for Dental Education in Europe. Aug 2006;10(3):149-156.

17. Long AF, Mercer PE, Stephens CD, Grigg P. The evaluation of three computer-assisted learning packages for general dental practitioners. British dental journal. Dec 10-24 1994;177(11-12):410-415.

18. Pollard DJ, Davenport JC. An evaluation of training general dental practitioners in partial denture design using a computer-assisted learning program. British dental journal. Dec 10-24 1994;177(11-12):405-409.

19. Grigg P, Stephens CD. Computer-assisted learning in dentistry. A view from the UK. Journal of dentistry. Jul-Aug 1998;26(5-6):387-395.

20. Buchanan JA. Experience with virtual reality-based technology in teaching restorative dental procedures. Journal of dental education. Dec 2004;68(12):1258-1265.

21. LeBlanc VR, Urbankova A, Hadavi F, Lichtenthal RM. A preliminary study in using virtual reality to train dental students. Journal of dental education. Mar 2004;68(3):378383.

22. Welk A, Maggio MP, Simon JF, et al. Computer-assisted learning and simulation lab with 40 DentSim units. International journal of computerized dentistry. 2008;11(1):1740 .

23. Haj-Ali R, Feil P. Rater reliability: short- and long-term effects of calibration training. Journal of dental education. Apr 2006;70(4):428-433.

24. Robertello FJ, Pink FE. The effect of a training program on the reliability of examiners evaluating amalgam restorations. Operative dentistry. Mar-Apr 1997;22(2):57-65.

25. Natkin E, Guild RE. Evaluation of preclinical laboratory performance: a systematic study. Journal of dental education. Jun 1967;31(2):152-161.

26. Patridge MI, Mast TA. Dental clinical evaluation: a review of the research. Journal of dental education. Jun 1978;42(6):300-305.

27. Polyzois I, McLouglin J, Kelly A, Claffey N. Clinical teaching in restorative dentistry and the variation between students' and supervisors' perceptions of its effectiveness. 
European journal of dental education : official journal of the Association for Dental Education in Europe. May 2010;14(2):92-98.

28. Lilley JD, ten Bruggen Cate HJ, Holloway PJ, Holt JK, Start KB. Reliability of practical tests in operative dentistry. British dental journal. Sep 3 1968;125(5):194-197.

29. Feil PH. An analysis of the reliability of a laboratory evaluation system. Journal of dental education. Aug 1982;46(8):489-494.

30. Scruggs RR, Daniel SJ, Larkin A, Stoltz RF. Effects of specific criteria and calibration on examiner reliability. Journal of dental hygiene : JDH / American Dental Hygienists' Association. Mar-Apr 1989;63(3):125-129.

31. Salvendy G, Hinton WM, Ferguson GW, Cunningham PR. Pilot study on criteria in cavity preparation--facts or artifacts? Journal of dental education. Nov 1973;37(11):2731. 


\section{MANUSCRIPT}

\section{Introduction}

Operative dentistry concepts and techniques are initially introduced to first year dental students through participation in a preclinical operative dentistry course. The course contains a didactic portion during which students learn the theoretical aspects of operative dentistry. The students rely on multiple faculty for application, reinforcement and enhancement of theoretical principles during a simultaneous laboratory portion of the course. Faculty members teaching the course are expected to provide consistent formative and summative feedback of the student performance. Low agreement, with regard to assessment of student performance, among faculty may lead to student confusion and frustration. Attempts to increase faculty agreement through improved communication of specific performance criteria, rating scales, and/or training have met with inconsistent results. ${ }^{1}$ Few studies have carefully analyzed each of the components of the evaluation system being used so as to identify specific areas of low agreement and then taken targeted steps, through faculty calibration training, to improve agreement. ${ }^{2}$

Faculty reliability, also referred to as faculty calibration, may be defined as the level of agreement among multiple faculty that occurs while assessing student performance. ${ }^{3}$ Faculty calibration can be divided into interexaminer reliability and intraexaminer reliability. Interexaminer reliability measures the 
level of agreement among the examiners when they are examining the performance of the same group of students on the same task. ${ }^{4}$ Intraexaminer reliability describes the consistency of a single examiner in grading the same sample on multiple occasions. ${ }^{3}$ Studies in the field of faculty calibration have shown that establishing agreement among faculty members is difficult. This may be due to the inconsistent grading methods, differing rating scales and individual teaching philosophy ${ }^{5-9}$.

Operative Dentistry procedures accomplished in the clinical setting are generally assessed as either clinically acceptable or clinically unacceptable. However, the pre-clinical training of these procedures requires that they be further subdivided into individual components/steps so as to aid the student during the learning process. This allows assessment of conceptual understanding as well as the ability to implement each component of the procedure. Overall procedural competence may then be assessed as a net sum of all individual components.

A pilot study evaluating the level of faculty calibration, which occurred while assessing 13 components of first year dental student Class II amalgam preparations, was conducted at the University of North Carolina (UNC) in 2011 Each component of the Class II preparation had a set of specific criteria which defined clinically acceptable and clinically unacceptable levels of procedure accomplishment.. The student assessment form used for the study is shown in Table 1. 
It is generally accepted that levels of agreement should minimally exceed that which would happen by chance $(50 \%)$ alone. Therefore, for the purpose of this study, $60 \%$ was arbitrarily set as the minimum level of agreement and average percentage agreement that fell below $60 \%$ was considered poor. The average percentage agreement (mean and standard deviation with confidence intervals) for each of the 13 components assessed during the Pilot study are listed in Table 2.

Analysis of the assessments from the pilot study revealed six out of thirteen cavity preparation components had interexaminer reliability below $60 \%$ (Figure 1). The six components of Class II cavity preparation that needed further faculty calibration were as follows: 1) Proximal and Gingival Contact Clearance, 2) Retention Groove Placement, 3) Retention Groove Depth, 4) Preparation Margin Finish, 5) Preparation Margin Orientation and 6) Preparation Toilet. These various preparation features are described in further detail in materials and methods.

Evaluation of the pilot study suggested levels of inherent faculty calibration which were unacceptable for at least 6 of the 13 components of one Class II procedure. First year dental students learn multiple procedures during their pre-clinical courses. Therefore, it was deemed appropriate that further steps should be undertaken so as to identify areas of poor faculty calibration and target these areas with strategies designed to enhance agreement relative to the assessment of student performance. 


\section{Specific Aims:}

1. To identify the level of interexaminer reliability among pre-clinical operative dentistry faculty when assessing 32 (thirty two) Class II preparations performed by 1 st year dental students.

2. To develop targeted exercises designed to enhance the ability of faculty to discriminate among levels of student performance (discrimination exercises) of various procedural components where average agreement among faculty was found to be below $60 \%$ and to organize and present these discrimination exercises to individual faculty members as part of a calibration session.

3. To evaluate the ability of discrimination exercises (as revealed by inter- and intraexaminer reliability) to increase initial levels of faculty calibration in assessment of the components of Class II preparation performed by first year dental students accomplished during their pre-clinical operative dentistry course (referred to as Phase I).

4. To evaluate the ability of discrimination exercises (as revealed by inter- and intraexaminer reliability) to sustain an increase in levels of faculty calibration, in assessment of the components of Class II preparation performed by first year dental students accomplished during their pre-clinical operative dentistry course, over a time interval of at least 6 months (referred to as Phase II). 


\section{Materials and methods}

This was a longitudinal, non-randomized cohort study conducted during the period of 2011 - 2013 at the University of North Carolina School of Dentistry. This study was IRB exempt (\#12-0262) by the University of North Carolina's Institutional Review Board.

\subsection{Dentiform teeth}

According to the Webster's dictionary, the word 'Dentiform' is defined as having the shape of tooth or teeth. The dentiform teeth used for the current study were a model of tooth \#30 with MOD caries, model \# A27A-46U, Kilgore ${ }^{\circledR}$ International Inc. The dentiform teeth had been fabricated with a composite material crown, epoxy resin dentin contained simulated dentin caries. The enamel and dentin anatomy was morphologically similar to a natural mandibular first molar and the placement of the simulated caries was similar to that found in the Class II caries disease state.

\subsection{Panel of Examiners}

The panel of examiners consisted of 8 examiners of which, five were full time faculty members, one was part time faculty and two were graduate students in the Department of Operative Dentistry at the UNC School of Dentistry who were currently teaching principles of operative dentistry procedures, including Class II preparation design for amalgam restoration to first year dental students. The faculty had varied levels of teaching and clinical experience. The author conducted an individual calibration session with each examiner. 


\subsection{Selection of dentiform teeth}

Thirty two Class II preparations [representing ideal $(\mathrm{n}=8)$, acceptable $(\mathrm{n}$ $=8)$, correctable $(\mathrm{n}=8)$ and unacceptable $(\mathrm{n}=8)$ student performance] were randomly selected from a pool of 82 . The same 32 Class II preparations were assessed by the examiners as part of the Pilot, Phase I and Phase II parts of the study. The cavity preparations were completed by first year dental students as part of the pre-clinical operative dentistry course. The students were instructed to prepare an ideal (according to specific criteria) MOD cavity preparation for amalgam restoration, with complete removal of the simulated caries lesion. The preparations were accomplished in the simulation laboratory designed to replicate the clinical setting. The dentiform tooth \#30 was placed in the dentiform with adjacent teeth (tooth \# 29 and \# 31) forming proximal contact points, during the preparation. The criteria for cavity preparation were adopted from Sturdevant's Art and Science of Operative Dentistry, $5^{\text {th }}$ Edition. ${ }^{10}$

\subsection{Calibration Session}

The duration of the calibration session was 20-40 minutes and utilized discrimination exercises to bring clarity to various levels of student performance on components identified as having low faculty calibration. The discrimination exercises included 3D demonstration models of actual dentiform teeth with various levels of student performance of preparation components as well as and digital images of component performance organized in the form of a Microsoft PowerPoint presentation. At the end of the PowerPoint presentation, a detailed discussion was conducted with the faculty member regarding the 
specific criteria outlined for each component of Class II cavity preparation as it appeared in the evaluation form.

\subsection{Discrimination Exercise Rationale}

Visual and tactile exercises were designed in an effort to enhance identification of ideal performance of individual procedural component and discrimination of variations from the ideal.

\subsection{Discrimination Exercise Design}

Discrimination exercises were designed for 5 out of 6 components that the pilot study had identified as having poor interexaminer reliability The o5 components were 1) Proximal and Gingival Contact Clearance, 2) Retention Groove Placement, 3) Retention Groove Depth, 4) Preparation Walls and 5) Preparation Margin Orientation. A discussion of the specific criteria for the component 'Preparation Toilet' was completed but no other discrimination exercise was developed for this component. The description and design of the five discrimination exercises are as follows:

\subsubsection{Proximal Contact Clearance}

A brief review of the desired final location of the facial and lingual walls of the proximal box was provided to each faculty member. A demonstration of how proximal contact clearance is measured at the proximal height of contour was provided. Review of the specific criteria defining levels of component performance was accomplished. Discussion included how the ideal proximal clearance is defined as visibly open and/or is open up to but not exceeding 0.75 
$\mathrm{mm}$ on either one or both the proximal walls as well as the specifics of student performance that varied from the ideal and how this was to be assessed. ${ }^{10}$

In an attempt to find an objective means of standardizing the assessment of proximal clearance, digital images (Nikon D3100 camera, Nikkor $105 \mathrm{~mm}$ Lens, Sigma EM-140 DG flash) of 82 Premier UNC 15 periodontal probes were taken. The mean diameter of the probes $(\mathrm{mm})$ was assessed using Image $\mathrm{J} \circledast$ (National Institutes of Health, Bethesda, Md) software.

The mean diameter of the UNC 15 probe was found to be $0.5( \pm 0.02) \mathrm{mm}$ at the 4-5 $\mathrm{mm}$ mark and $0.75( \pm 0.02) \mathrm{mm}$ at the $11-12 \mathrm{~mm}$ mark (Figure 2.1). The UNC-15 periodontal probe was therefore adopted as a standardized measurement device for the purpose of assessing proximal contact clearance. The discrimination exercise included a tactile demonstration of how the proximal contact clearance is be assessed as ideal, if the diameter of the periodontal probe at the $4 / 5 \mathrm{~mm}$ mark (up to $0.5 \mathrm{~mm}$ ) cannot pass between the proximal surfaces, acceptable if the clearance between the proximal surfaces was between the $5 \mathrm{~mm}$ mark and the $11 / 12 \mathrm{~mm}$ mark (between $0.5 \mathrm{~mm}$ and $0.75 \mathrm{~mm}$ ) and/or clinically unacceptable, if the clearance between the proximal surfaces is greater than the diameter of the periodontal probe at the $11 / 12 \mathrm{~mm}$ mark $(>0.75$ $\mathrm{mm}$ ) between the proximal contact clearances (Figures 2.2 and 2.3).

\subsubsection{Retention Groove Placement}

Retention grooves are considered secondary retentive features that may be included in preparation design for retention of anticipated restoration in the proximal areas of the preparation. The ideal placement of retention grooves 
should theoretically be placed approximately $0.2 \mathrm{~mm}$ internal to the dentinoenamel junction (DEJ) on the facial and lingual proximal preparation walls as this would ensure sufficient amount of supported enamel and avoid injury to the pulp. ${ }^{10}$

Students may incorrectly place retention grooves. Therefore the discrimination exercise included a series of Class II preparations with different axial wall depths that represented the various types of errors found in student preparations. The dentiform teeth were sectioned sagitally so as to allow visualization of the gingival and facial external walls, the axial and pulpal internal walls and various positions of retention grooves (Figures 3.1-3.7). The preparations were as follows:

Preparation\#1: Ideal axial wall depth $(0.5 \mathrm{~mm}$ inside the DEJ) with a retention groove in the enamel facial wall indicating a clinically unacceptable position (Figure 3.1).

Preparation\#2: Ideal axial wall depth $(0.5 \mathrm{~mm}$ inside the DEJ $)$ with a retention groove placed at the DEJ indicating a clinically unacceptable position (Figure $3.2)$.

Preparation\#3: Ideal axial wall depth $(0.5 \mathrm{~mm}$ inside the DEJ) with retention groove placed $\sim 0.2 \mathrm{~mm}$ internal to the DEJ indicating a clinically acceptable position (Figure 3.3).

Preparation\#4: Ideal axial wall depth $(0.5 \mathrm{~mm}$ inside the DEJ) with retention groove placed in the axial wall indicating clinically an unacceptable position (Figure 3.4). 
Preparation\#5: Ideal axial wall depth $(0.5 \mathrm{~mm}$ inside the DEJ) with retention groove placed in the gingival floor indicating a clinically unacceptable position (Figure 3.5).

Preparation\#6: Deep axial wall $(\sim 2 \mathrm{~mm}$ inside the DEJ) with retention groove placed $0.2 \mathrm{~mm}$ internal to the DEJ indicating a clinically acceptable position (Figure 3.6).

Preparation\#7: Deep axial wall (2mm inside the DEJ) with retention groove placed at the axial and facial wall line angle indicating a clinically unacceptable position (Figure 3.7).

\subsubsection{Retention Groove Depth:}

Students may create a retention groove that has incorrect depth. The groove should ideally be $0.1-0.5 \mathrm{~mm}$ deep to ensure adequate retention. ${ }^{10}$

A discrimination exercise provided examiners with an explorer and three sagitally sectioned dentiform teeth, with Class II preparations, that contained retention grooves that were deep $(>0.5 \mathrm{~mm}$ in depth), ideal $(0.1-0.5 \mathrm{~mm}$ in depth) and shallow (<0.1 $\mathrm{mm}$ in depth, undetectable). Deep or shallow retention grooves were deemed unacceptable. No digital images were used to enhance discrimination of various levels of performance of this component.

\subsubsection{Preparation Finish}

Students may fail to pay close attention to subtle detail as they create cavity preparations. Unsupported enamel associated with cavosurface margins, rough preparation walls and sharp internal line angles may compromise the placement and longevity of the restoration. Preparation Finish involves 
smoothing of the external walls to eliminate any unsupported enamel and rounding the internal line angles to avoid stress concentration. ${ }^{10}$

A discrimination exercise provided the examiners with four Class II cavity preparations that contained the various combinations of student performance of preparation wall finish. Each combination was identified as clinically acceptable or unacceptable. The preparation finish combinations were as follows:

1) Preparation finish resulting in smooth walls and gentle transitions clinically acceptable (Figures $4.1 \& 4.2$ ).

2) Preparation finish resulting in smooth walls and abrupt transitions clinically unacceptable (Figures $4.3 \& 4.4$ ).

3) Preparation finish resulting in rough walls and abrupt transitions clinically unacceptable (Figures $4.5 \& 4.6$ ).

4) Preparation finish resulting in rough walls and gentle transitions clinically unacceptable (Figures $4.7 \& 4.8$ ).

\subsubsection{Preparation Margins :}

Students may create Class II cavity preparations with cavosurface margin angles that are $<80$ degrees $\left(^{\circ}\right)$, are $90^{\circ}$ or are $>100^{\circ}$. The cavosurface angle is the angle of the tooth structure formed by the junction of a prepared (cut) wall and the external surface of the tooth. The actual junction is referred to as cavosurface margin. Enamel cavosurface margins of Class II cavity preparations require dentin support. External preparation walls that are aligned parallel to 
average enamel rod orientation will result in cavosurface margin angles that are approximately $90^{\circ} \cdot{ }^{10}$

Proximal external walls that are oriented at $90^{\circ}$ to a tangent aligned with the external curvature of the tooth are considered to have enamel that is supported by enamel. A $90^{\circ}$ proximal wall orientation is considered clinically acceptable. Proximal external walls that are oriented $<80^{\circ}$ to a tangent aligned with the external curvature of the tooth are considered to have enamel that is not supported by dentin. A proximal wall orientation that is $<80^{\circ}$ is considered clinically unacceptable. Proximal external walls that are oriented $>100^{\circ}$ to a tangent aligned with the external curvature of the tooth will result in an amalgam restoration margin that is fragile. A proximal wall orientation that is > $100^{\circ}$ is considered clinically unacceptable.

Discrimination exercises consisted of digital images of clinically acceptable and unacceptable proximal wall orientations. A transparent protractor was superimposed over the images to enable more objective identification of wall orientations that were $<80^{\circ}$, were approximately $90^{\circ}$ or were $>100^{\circ}$. (Figures 5.1, 5.2 and 5.3). Examples of clinically acceptable and unacceptable cavosurface margin orientations, including ideal cavosurface margins $\left(90^{\circ}\right)$ were presented and discussed during this discrimination exercise.

\subsection{Review of the Assessment Rubric}

Following the Microsoft PowerPoint presentation, detailed discussion of the 13 components of a Class II cavity preparation and the specific criteria defining levels of student performance for each component listed on the 
assessment rubric form was completed. Examiners were provided opportunity to ask questions throughout the calibration session.

\subsection{Timing of the Phase I and Phase II Assessments}

\subsubsection{Phase I Assessment}

Each examiner was asked to assess the 32 Class II cavity preparations immediately after completion of the calibration session. The assessment required approximately 2-3 hours and was accomplished in one sitting.

\subsubsection{Phase II Assessment}

The examiners assessed the same 32 Class II preparations after an average time interval of 6 months. The assessment was conducted using the same controlled settings as the Pilot and Phase I studies. However, no calibration session was provided. The purpose of the Phase II assessment was to evaluate the impact of the passage of time on levels of examiner calibration.

\subsection{Organization of the Data}

The Class II preparation assessment point values were transferred by the primary investigator from the assessment rubrics to a digital file (Table 3 ). An independent investigator coded the names of the examiners using alphabets letters from ' $A$ ' to ' $H$ ' so that the primary investigator was blinded to examiner identity. The data was then subjected to statistical analysis.

\section{Statistical Analysis}

The concordance and discordance between each pair of examiners were analyzed using Weighted Kappa and McNemar analysis. The interexaminer reliability was as average percentage agreement among the 8 examiners for the 
Pilot study, Phase I and Phase II. The confidence interval (CI) was calculated for each component of the cavity preparation for all 3 assessment sessions.

\section{Results}

\subsection{Interexaminer Reliability- Phase I}

The interexaminer reliability, reported as average percentage agreement, among the examiners increased for 7 out of the 13 components when compared to the results of the pilot study. However, for 3 components (Adjacent Tooth Damage, Unsupported Enamel and Primary/Axial Wall Depth) the average percentage agreement did not change and for another 3 components (Occlusal Convergence, Retention Groove Placement and Retention Groove Depth) there was a decline in average percentage agreement (Figure 6).

Assessment of some components targeted with discrimination exercises showed increase levels of faculty calibration whereas assessment of other components did not. The average percentage agreement increased for Proximal Contact Clearance from $52 \%$ before the calibration session to $70 \%$ after calibration session with $95 \% \mathrm{CI}$ at $[(68.79,80.54)]$. The average interexaminer agreement for Retention Groove Placement decreased 58 to 53\% [95\% CI $(46.15,59.97)]$ and for Retention Groove Depth decreased from 57 to $56 \%$ [95\%

CI $(51.03,61.03)]$. The average interexaminer agreement for Preparation Wall Finish increased from 59 to $65 \%$ [95\% CI $(54.16,68.62)]$,, for Preparation Margin Orientation increased from 54 to $63 \%$ [95\% CI $(58.13,67.32)$ ] and for Preparation Debris increased from 58 to $68 \%$ [95\% CI $(63.80,72.81)]$. The 
confidence interval for each of the 13 components after the calibration session is reported in Table 4 .

\subsection{Intraexaminer Reliability - Pilot Study to Phase I}

The average intraexaminer agreement among the course faculty was $74(+/-5) \%$. The intraexaminer reliability (agreement of each examiner with themselves) was calculated as average intraexaminer agreement (\%) when comparing Pilot study to Phase I. The results are listed in Table 5. Assessment of the 13 preparation components varied greatly from Pilot to Phase I. The component 'Enamel Present' had the lowest intraexaminer variation and the component 'Proximal Contact Clearance' had the highest intraexaminer variation (Figures 7 and 8 ). Table 6 shows the level of intra-examiner variation for each examiner for all 13 components between the Pilot study and Phase I.

\subsection{Interexaminer Reliability - Phase II}

The interexaminer agreement began to decline for 8 out of the 13 components after an average time interval of 6 months. For 3 components (Adjacent Tooth Damage, Retention Groove Placement and Retention Groove Depth) there was a slight increase (1-3\%) in average percentage agreement among the examiners. The average percentage agreement among the examiners stayed the same for one component (Occlusal Convergence). However, for 2 components (Isthmus Width and Preparation Toilet) the inter examiner reliability continued to increase compared to Pilot study and Phase I (Figure 9).

The results of the components for which discrimination exercises were designed are as follows: average interexaminer agreement decreased for 
'Proximal Contact Clearance' from 70\% after calibration exercises to $60 \%$ [95\% CI $(53.38,67.17)]$ after an average time interval of 6-7 months. The average interexaminer agreement decreased from 58 to $53 \%$ [95\% CI $(46.15,59.97)$ ] for 'Retention Groove Placement' and 57 to 56\% [95\% CI $(51.03,61.03)]$ for 'Retention Groove Depth'. The average interexaminer agreement increased from 59 to $64 \%$ [95\% CI $(54.16,68.62)]$ for 'Preparation Wall Finish', 54 to $63 \%$ [95\% CI $(58.13,67.32)]$ for 'Preparation Margin Orientation' and 58 to $68 \%$ [95\% CI $(63.80,72.81)]$ for 'Preparation Debris'. The average percentage agreement and confidence interval for assessment of each component of the cavity preparation during Phase II is reported in Table 7.

\subsection{Intraexaminer Reliability - Phase II}

The average intraexaminer agreement among the course faculty was 77 $(+/-7) \%$ when comparing Pilot study to Phase II and $76(+/-8) \%$ when comparing Phase I to Phase II. The intraexaminer reliability was calculated for Pilot Study: Phase I and Phase I: Phase II comparisons (Tables $8 \&$ 9). While some examiners remained consistent in their assessment patterns from Phase I to Phase II, the others reverted back to assessing with a variation of $30-40 \%$ for a few components. Assessment of 'Isthmus Width' had the lowest intraexaminer variation and assessment of 'Proximal Contact Clearance' had the highest intraexaminer variation (Figures 10 and 11). Comparison of the intraexaminer variation that occurred while assessing all 13 components when comparing Phase I: Phase II and the Pilot Study: Phase II and Phase I: Phase II respectively. 
The level of intraexaminer variation (\%) for all 13 components of Class II cavity preparation for each examiner when comparing Pilot study to Phase II is shown in Table 10 and the level of intraexaminer variation (\%) for all 13 components of Class II cavity preparation for each examiner when comparing Phase I to Phase II is shown in Table 11.

\section{Discussion:}

It has been well documented that improving the level of agreement among faculty members is not an easy task. ${ }^{5,7,11}$. The over-arching goal of the current study was to determine the interexaminer and intraexaminer reliability while assessing 13 components of a preclinical operative procedure completed by first year dental students and to seek to increase faculty agreement in areas where it was low. The results of the pilot study confirmed that there were areas of low interexaminer agreement among the faculty. As part of the study design, specific exercises were developed and presented in a calibration session so as to increase the ability of faculty to discriminate among various levels of student performance. The efficiency of these exercises was evaluated through the use of immediate (Phase I) and delayed (Phase II) inter-and intraexaminer reliability testing.

The concordance and discordance between each pair of examiners were analyzed using Weighted Kappa and McNemar analysis. A weakness of the standard Kappa statistic is that all disagreements are treated equally. Unlike the standard Kappa analysis, the Weighted Kappa statistic measures the degree of agreement. For example, as stated by Viera and Garett, we may not care whether 
one radiologist categorizes a mammogram finding as normal and another categorizes it as benign, but we do care if one categorizes it as normal and the other as cancer ${ }^{12}$. Similarly for the current study, if we look at the component Proximal contact clearance a disagreement between 'No Clearance' and 'Open up to $0.5 \mathrm{~mm}$ in all directions' is not as severe as one between 'No Clearance' and 'Open more than $0.75 \mathrm{~mm}$ in any direction'.

Proximal contact clearance is traditionally identified by the appearance of a visually open clearance at the proximal height of contour. Assessment of the distance of proximal clearance is vague and subject to personal bias.

Dimitrijevic et al examined dentists' and dental students' abilities to estimate small depths and distances and established that individual perceptual abilities vary widely. This study highlighted that some dentists and many dental students, particularly early in their course, have great difficulty in accurately gauging depths and distances. ${ }^{13}$ Course faculty must ensure students receive objective, unbiased assessment of their performance.

The results from Phase I showed that the interexaminer reliability improved with the use of discrimination exercises. As part of the discrimination exercises, the use of UNC 15 periodontal probe was introduced in a novel way so as to more objectively assess proximal contact clearance. The average percentage agreement among the examiners increased from $52 \%$ before calibration to $70 \%$ after calibration for this component. After an average time interval of 6 months, the percentage of inter examiner agreement decreased to $60 \%$ for this component but still remained higher than the Pilot study. It may be 
that introduction of a specific instrument to assess this component contributed to the increase in interexaminer reliability, and limited the influence of personal examiner bias associated with the assessment of this component.

There was also an increase in interexaminer reliability for components such as 'Isthmus Width' and 'Preparation Debris' for which no discrimination exercises were designed. The authors speculate that detailed discussions regarding the specific criteria outlined for all 13 components of the Class II preparation may have helped to limit mis-understanding of subjective interpretation of these criteria.

The two components for which there was no increase in reliability among the examiners were retention groove placement and retention groove depth. This was in spite of examiner participation in carefully designed discrimination exercises. Although studies have been done on the significance, ideal position and ideal depth of retention grooves, researchers have not been able to achieve consensus. $^{11-13}$

A survey by David Moore in 1992 investigated the teaching in dental schools regarding proximal retention grooves in Class II cavity preparations for amalgam restoration. He included 64 schools across the US and Canada. The response rate was $92 \%$ (59 schools) out of which $61 \%$ (36 schools) of the schools responded 'YES' to teaching retention grooves and 39\% (23 schools) of the schools responded ' $\mathrm{NO}$ ' to teaching this technique ${ }^{14}$.

The results of the current study also showed increased intraexaminer variations for the components 'Retention groove placement' and 'Retention 
groove depth'. These increased variations prompted us to conduct an informal2013 survey of the nation's dental schools to inquire if they regularly taught the placement of retention grooves in conservative Class II cavity preparations for amalgam restoration. The questionnaire was emailed to 65 dental schools across the nation. The response rate was $53(82 \%)$. Of the 53 schools that responded 24 of them replied 'YES' and 29 of them replied 'NO' to the teaching of retention grooves. It may be that variations in the professional philosophy (on the use of retention grooves) of the examiners included in this study limited the ability to increase the level of agreement in assessing these components. It is important to note that both the placement and accurate assessment of retention grooves is difficult.

Although there was a rise in average percentage agreement among the examiners after the calibration, the results of the Phase II grading session, revealed a definite decline in interexaminer reliability. The study did not test for the point in time when the level of reliability started to decline but only detected that there was a decline at an average time interval of 6 months. This piece of information is valuable and can be translated as a need for frequent calibration sessions throughout the academic year.

A limitation of this study is that it does not evaluate intraexaminer variation based on the clinical and teaching experience of the examiners. Jenkins et al found that the level of pass-fail differences (intraexaminer variability) in their study seemed to be unrelated to the experience of the examiner, with even the senior examiner recording differences of $17 \%^{8}$. Another 
study reported that it is theoretically possible that examiner variability alone may result in some unfortunate undergraduate student failing on more than one occasion particularly if acknowledged that on a different day, the same cavity, assessed by the same examiner, may well have passed ${ }^{8}$. An excerpt from Mackenzie's article on defining clinical competence in terms of quality, quantity and need for performance criteria, clearly states the problem of intraexaminer variability; "A dental student reported the following event. A good student and a poor student were sitting next to each other in a basic technics laboratory. The good student finished the preparation in an ivorine tooth and took it to the instructor. The instructor said, "fine work", and gave him an 'A'. A little while later the poor student tooth the 'A graded' tooth to the same instructor. The instructor looked at it, said, "Hm-mm, OK," and gave him a ${ }^{\prime} C^{15}$.

Another limitation of this study is that the results may be negatively influenced from examiner fatigue. Examiner fatigue may play a major role in the decline of interexaminer reliability. Having to grade large number of samples at one time may cause the examiner to lose focus. As suggested by Dhuru, Rypel and Johnston ${ }^{3}$ future studies should limit the number of preparation samples or have the examiners take frequent breaks after grading 10-15 samples.

The results of the current study indicate that discrimination exercises are beneficial for faculty calibration. Future efforts in the field of faculty calibration should focus on designing instruments to aid in objective evaluation of student performance. The results also highlighted a need for more frequent 
calibration sessions. There is a potential benefit in designing calibration sessions as online CE courses, because, they can be used by students and faculty as often as needed for self-analysis.

In summary, the overall interexaminer reliability improved after calibration. The results showed that, the objective use of an instrument (UNC 15 periodontal probe) increased interexaminer reliability. The study supports the use of discrimination exercises for faculty calibration in order to improve the consistency of faculty-student communication. The study findings reveal a decrease in inter and intra-examiner reliability at 6 months. Wide intraexaminer variation was noted from Pilot Study to Phase I. Even though variations were noted in intraexaminer reliability after a time interval of 6 months, the degree of variation was lower than Pilot Study: Phase I.

\section{Conclusions:}

- Overall interexaminer reliability improved after calibration.

- The objective use of an instrument (UNC 15 periodontal probe) increased interexaminer reliability.

- The study findings reveal a decrease in inter and intra-rater reliability at 6 months. This suggests that having more frequent calibration sessions may be beneficial for maintaining an optimum level of calibration among the course faculty. However this notion was not tested. 
TABLE 1 - Class II Amalgam Procedure Performance Assessment Rubric Used For The Pilot Study, Phase I And Phase II

\begin{tabular}{|c|c|}
\hline EXTERNAL OUTLINE & \\
\hline Caries Removal & $\begin{array}{l}\text { Complete removal at the DEJ } \\
\text { Incomplete removal at DEJ }\end{array}$ \\
\hline Isthmus Width & $\begin{array}{l}\text { Less than } 1 \mathrm{~mm} \\
\text { Between } 1 \mathrm{~mm} \text { and } 1 / 3 \text { of intercuspal distance } \\
\text { Between } 1 / 3 \text { and } 1 / 2 \text { of intercuspal distance } \\
\text { Greater than } 1 / 2 \text { of intercuspal distance }\end{array}$ \\
\hline Proximal Contact Clearance & $\begin{array}{l}\text { No Clearance } \\
\text { Open up to } 0.5 \mathrm{~mm} \text { in all directions } \\
\text { Open between } 0.5 \text { and } 0.75 \mathrm{~mm} \text { in any direction } \\
\text { Open more than } 0.75 \mathrm{~mm} \text { in any direction }\end{array}$ \\
\hline Adjacent Tooth Damage & $\begin{array}{l}\text { No damage } \\
\text { Requires re-contouring } \\
\text { Requires restoration }\end{array}$ \\
\hline \multicolumn{2}{|l|}{ INTERNAL FORM } \\
\hline Enamel Present & $\begin{array}{l}\text { None } \\
\text { Less than or equal to } 50 \% \text { of preparation } \\
\text { Greater than } 50 \% \text { of preparation }\end{array}$ \\
\hline Primary Pulpal/Axial Wall & $\begin{array}{l}\text { Less than or equal to } 0.5 \mathrm{~mm} \text { internal to DEJ } \\
0.5-1.5 \mathrm{~mm} \text { internal to DEJ } \\
2.0-2.5 \mathrm{~mm} \text { internal to DEJ } \\
\text { Greater than } 2.5 \mathrm{~mm} \text { internal to DEJ }\end{array}$ \\
\hline Caries Removal & $\begin{array}{l}\text { Incomplete } \\
\text { Complete } \\
\text { Complete with excessive dentin removal }\end{array}$ \\
\hline \multicolumn{2}{|l|}{ RETENTION FORM } \\
\hline External Walls & $\begin{array}{l}\text { Occlusal convergence with } \sim 90^{\circ} \text { cavosurface margins } \\
\text { Excessive occlusal convergence with } \angle 90^{\circ} \text { cavosurface } \\
\text { margins } \\
\text { External walls parallel } \\
\text { External walls diverge occlusally }\end{array}$ \\
\hline Retention Groove Placement & $\begin{array}{l}\text { Undermined enamel } \\
\approx 0.2 \mathrm{~mm} \text { internal to } \mathrm{DEJ} \\
\text { Between } 0.2 \mathrm{~mm} \text { and } 1 \mathrm{~mm} \text { internal to DEJ } \\
\text { Greater than } 1 \mathrm{~mm} \text { internal to DEJ } \\
\text { Not Visible }\end{array}$ \\
\hline Retention Groove Depth & $\begin{array}{l}\text { Undetectable } \\
\text { Between } 0.1 \mathrm{~mm} \text { and } 0.5 \mathrm{~mm} \\
\text { Greater than } 0.5 \mathrm{~mm}\end{array}$ \\
\hline \multicolumn{2}{|l|}{ FINISHING } \\
\hline Preparation Walls & $\begin{array}{l}\text { Smooth, gentle transitions } \\
\text { Rough, abrupt transitions }\end{array}$ \\
\hline Preparation Margins & Unsupported enamel $\left(<80^{\circ}\right)$ \\
\hline
\end{tabular}




\begin{tabular}{|c|c|}
\hline & $\begin{array}{l}\text { Supported enamel }\left(90^{\circ}\right) \\
\text { Enamel margin }>100^{\circ}\end{array}$ \\
\hline Preparation Toilet & $\begin{array}{l}\text { Debris present } \\
\text { Clean }\end{array}$ \\
\hline 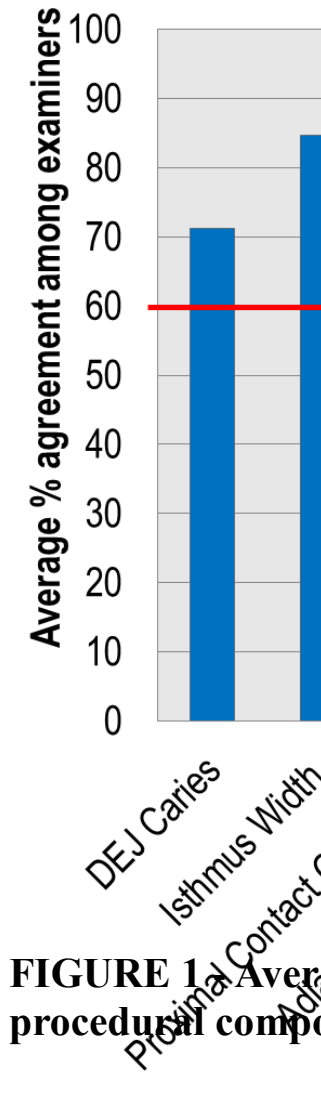 & 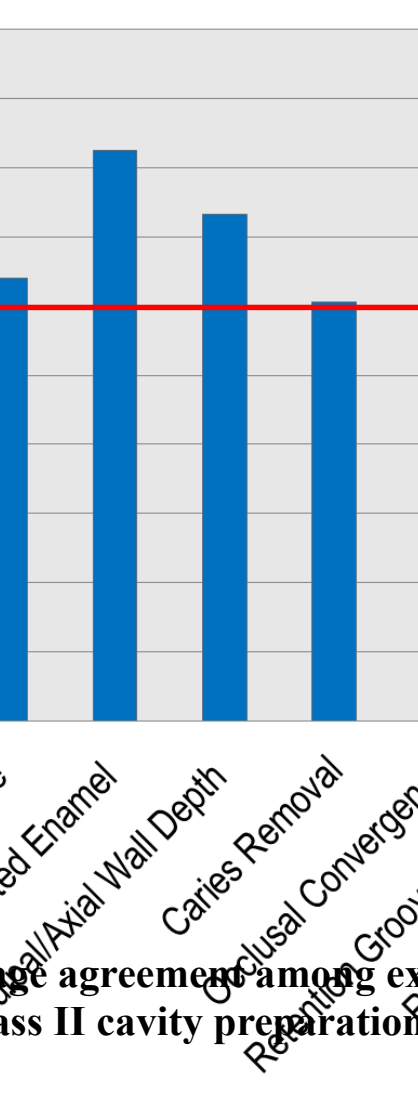 \\
\hline
\end{tabular}


TABLE 2 - Average percent agreement (mean +/- sd) and 95\% CI for assessment of components of Class II cavity preparation during the Pilot study

\begin{tabular}{|l|c|c|c|}
\hline \multicolumn{1}{|c|}{$\begin{array}{c}\text { 95\% CI } \\
\text { PREPARATION }\end{array}$} & $\begin{array}{c}\text { STD } \\
\text { DEV }\end{array}$ & $\begin{array}{c}\text { 95\% } \\
\text { (LOWER, UPPER) }\end{array}$ \\
\hline DEJ Caries & MEAN & & \\
Isthmus Width & 71.15 & 9.96 & $(67.29,75.01)$ \\
Proximal Contact Clearance & 84.73 & 10.76 & $(80.56,88.90)$ \\
Adjacent Tooth Damage & 52.01 & 25.83 & $(42.00,62.03)$ \\
Enamel Present & 63.95 & 14.14 & $(58.47,69.44)$ \\
Primary Pulpal Axial Wall & 82.48 & 25.10 & $(72.74,92.21)$ \\
Caries Removal & 73.22 & 12.01 & $(68.56,77.87)$ \\
External Walls & 60.60 & 14.92 & $(52.81,64.38)$ \\
Retentive Groove Placement & 66.97 & 11.66 & $(62.45,71.49)$ \\
Retention Groove Depth & 58.37 & 9.43 & $(54.72,62.03)$ \\
Preparation Walls & 57.37 & 11.10 & $(53.07,61.67)$ \\
Preparation Margins & 59.01 & 8.93 & $(57.04,63.96)$ \\
Preparation Toilet & 54.02 & 20.14 & $(46.21,61.83)$ \\
\hline
\end{tabular}




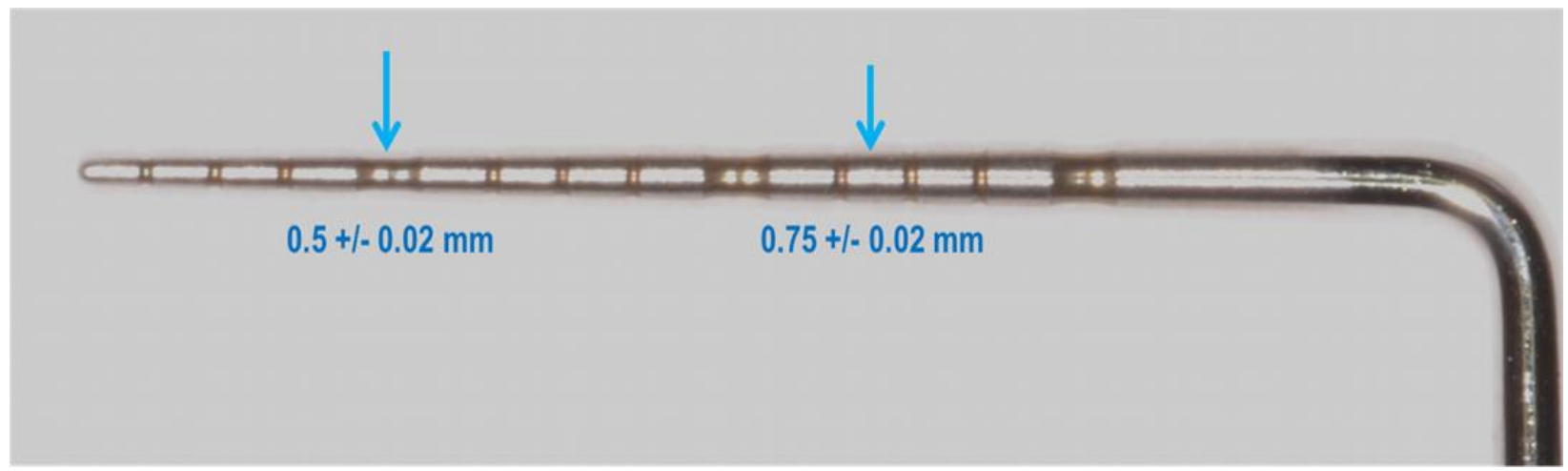

FIGURE 2.1- The mean diameter of the UNC 15 probe at the 4-5 mm mark was 0.5 +/0.02 and $0.75+/-0.02$ at the $\mathbf{1 1 - 1 2}$ mm mark. The measurements were made using the Image $\mathbf{J}$ software. 


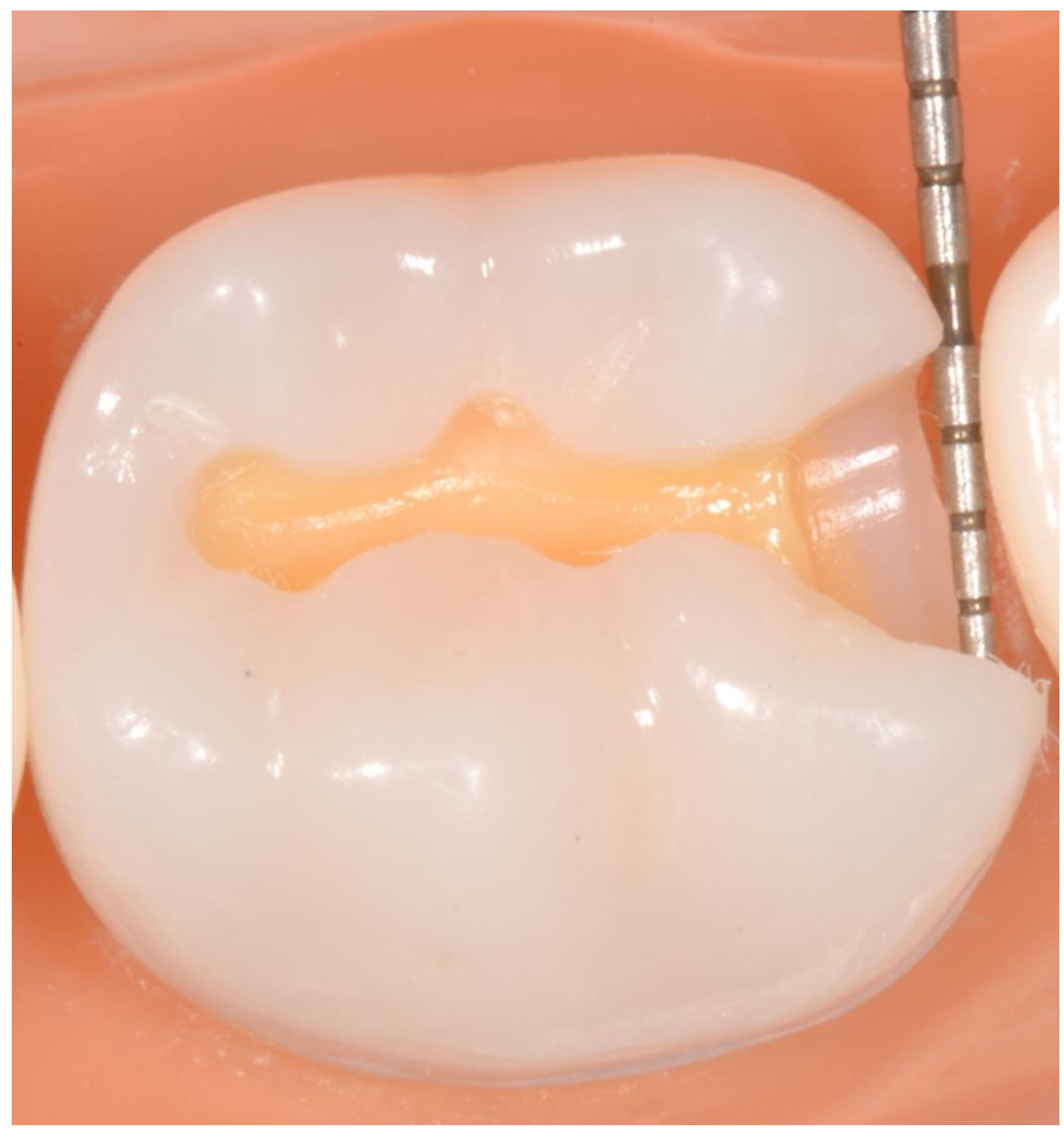

FIGURE 2.2- 3D model used to demonstrate clinically acceptable example of proximal contact clearance 


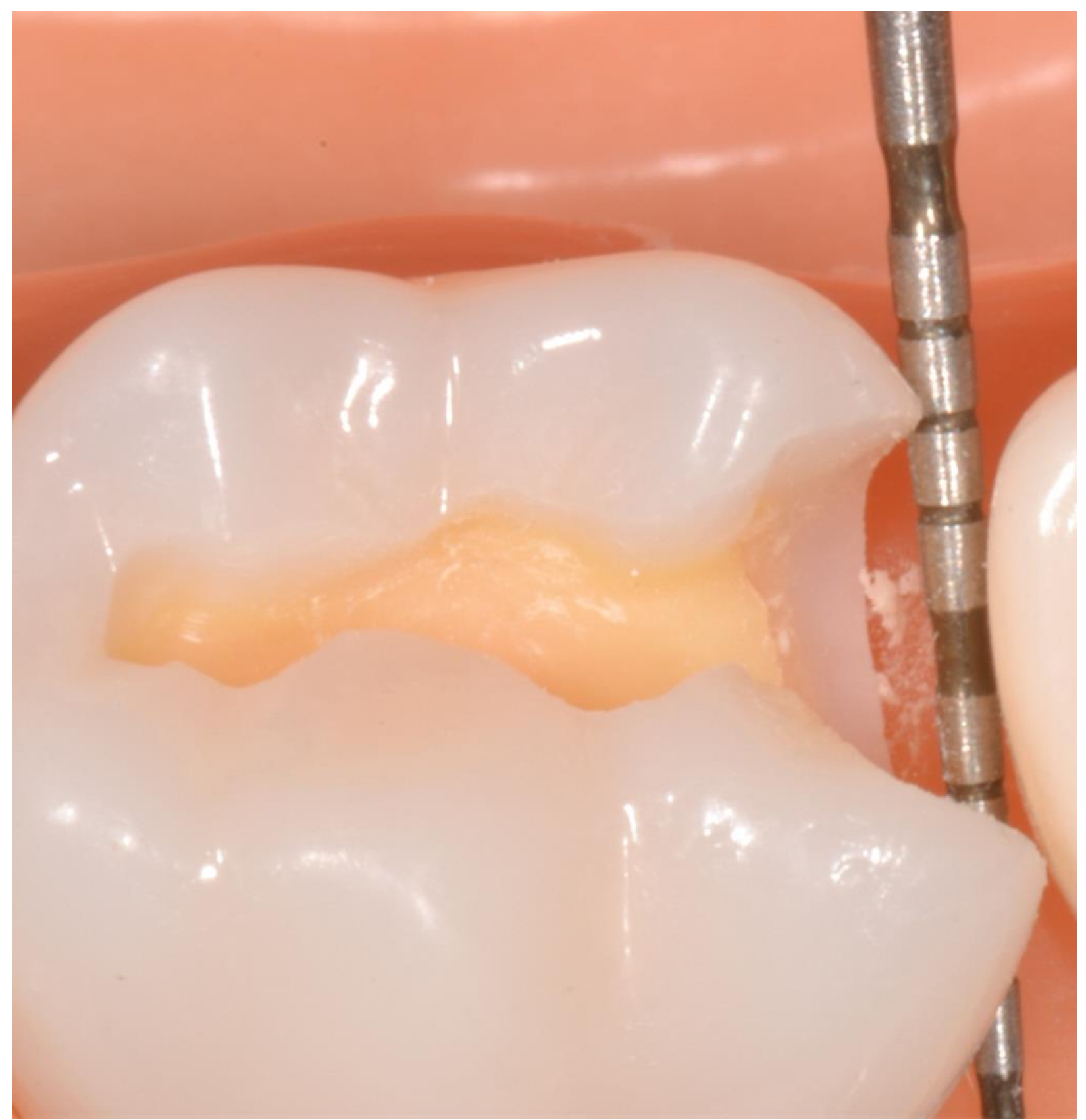

FIGURE 2.3- 3D model used to demonstrate clinically unacceptable example of proximal contact clearance 


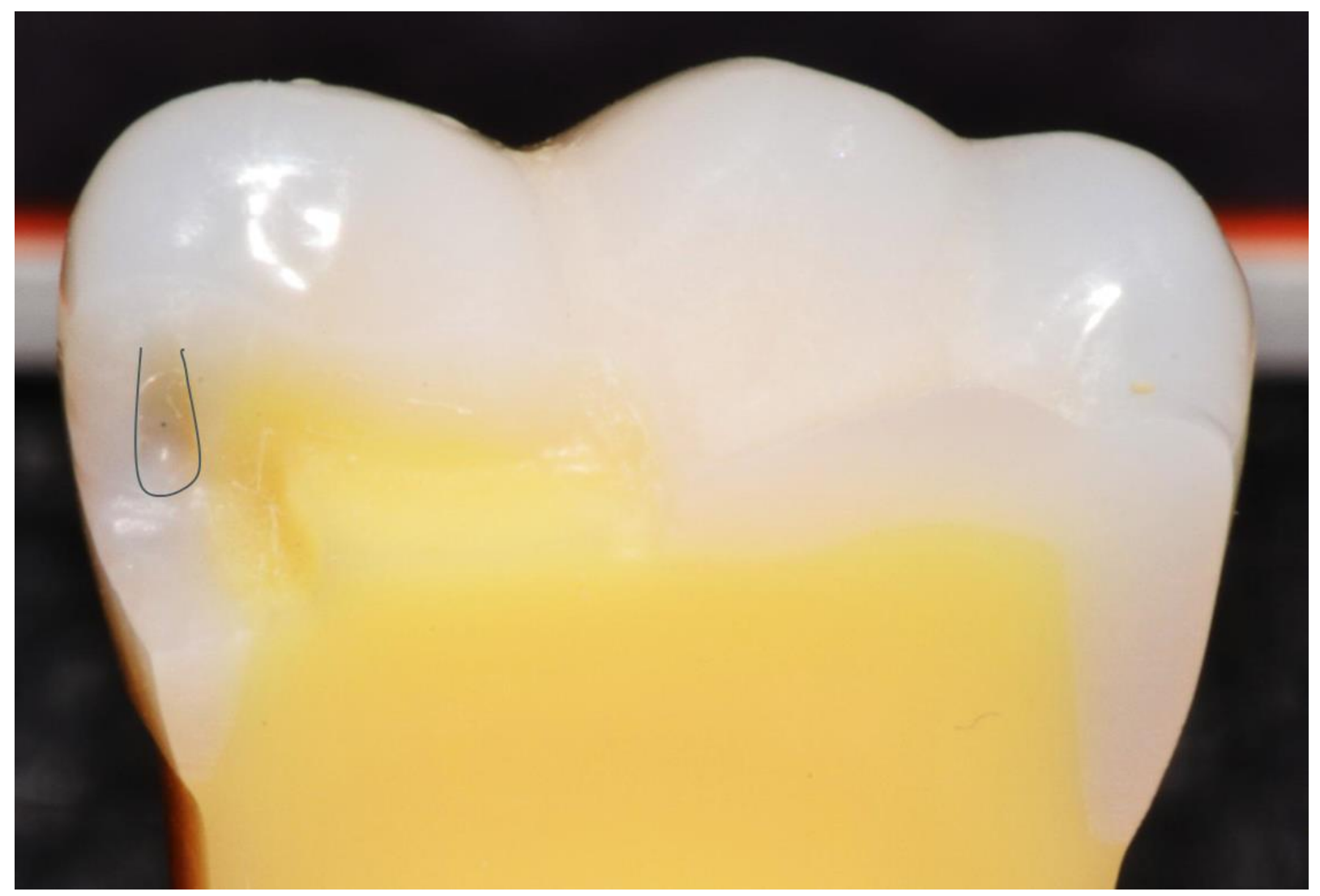

FIGURE 3.1- 3D model demonstrating clinically unacceptable retention groove placemen in the enamel facial wall of a preparation with ideal axial wall depth. 


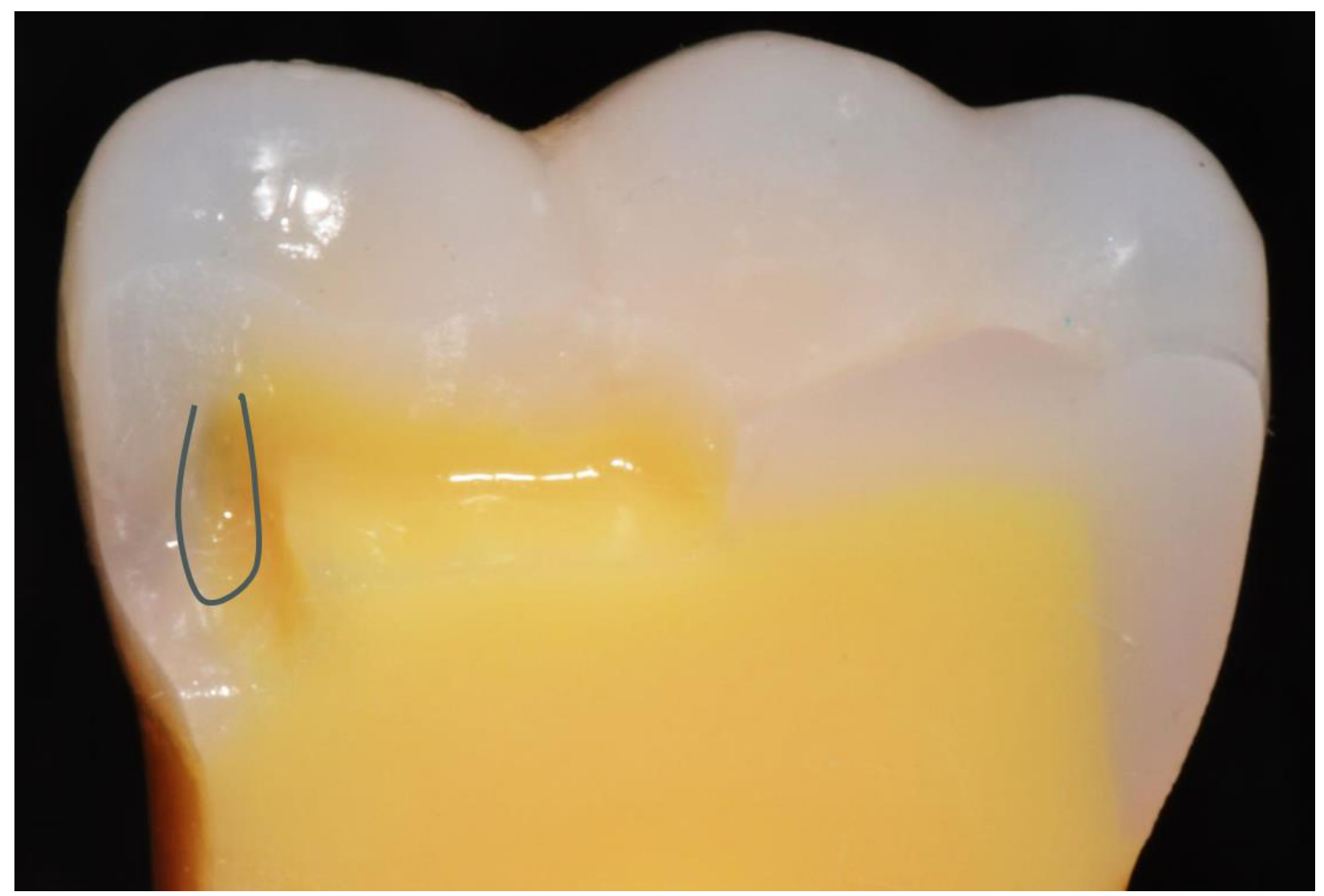

FIGURE 3.2- 3D model demonstrating clinically unacceptable retention groove placement at the DEJ of the facial wall of a preparation with ideal axial wall depth. 


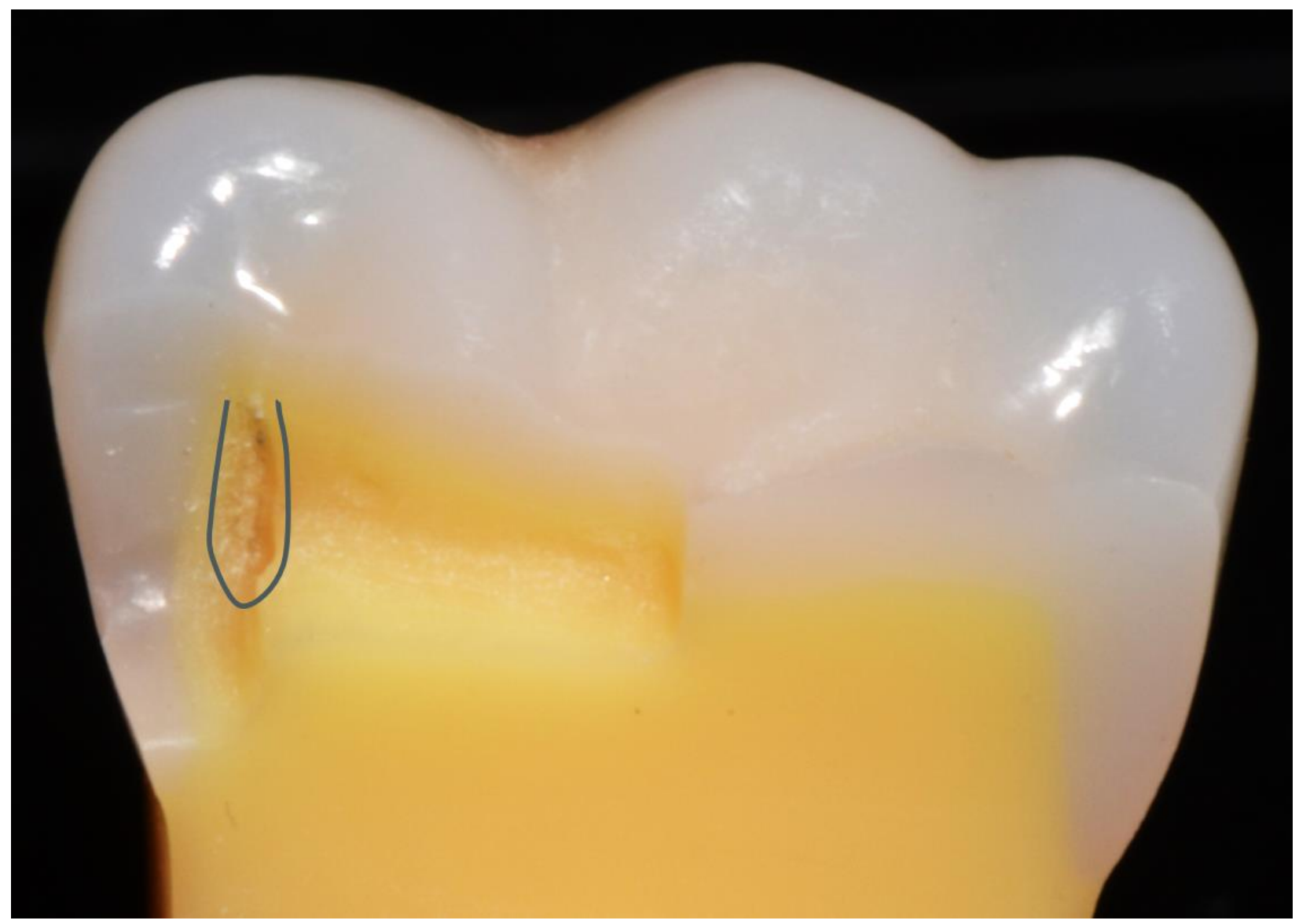

FIGURE 3.3- 3D model demonstrating clinically acceptable retention groove placement $\sim 0.2 \mathrm{~mm}$ internal to the DEJ such that it is partially in the dentin facial wall and partially in the adjacent axial wall of a preparation with ideal axial wall depth. 


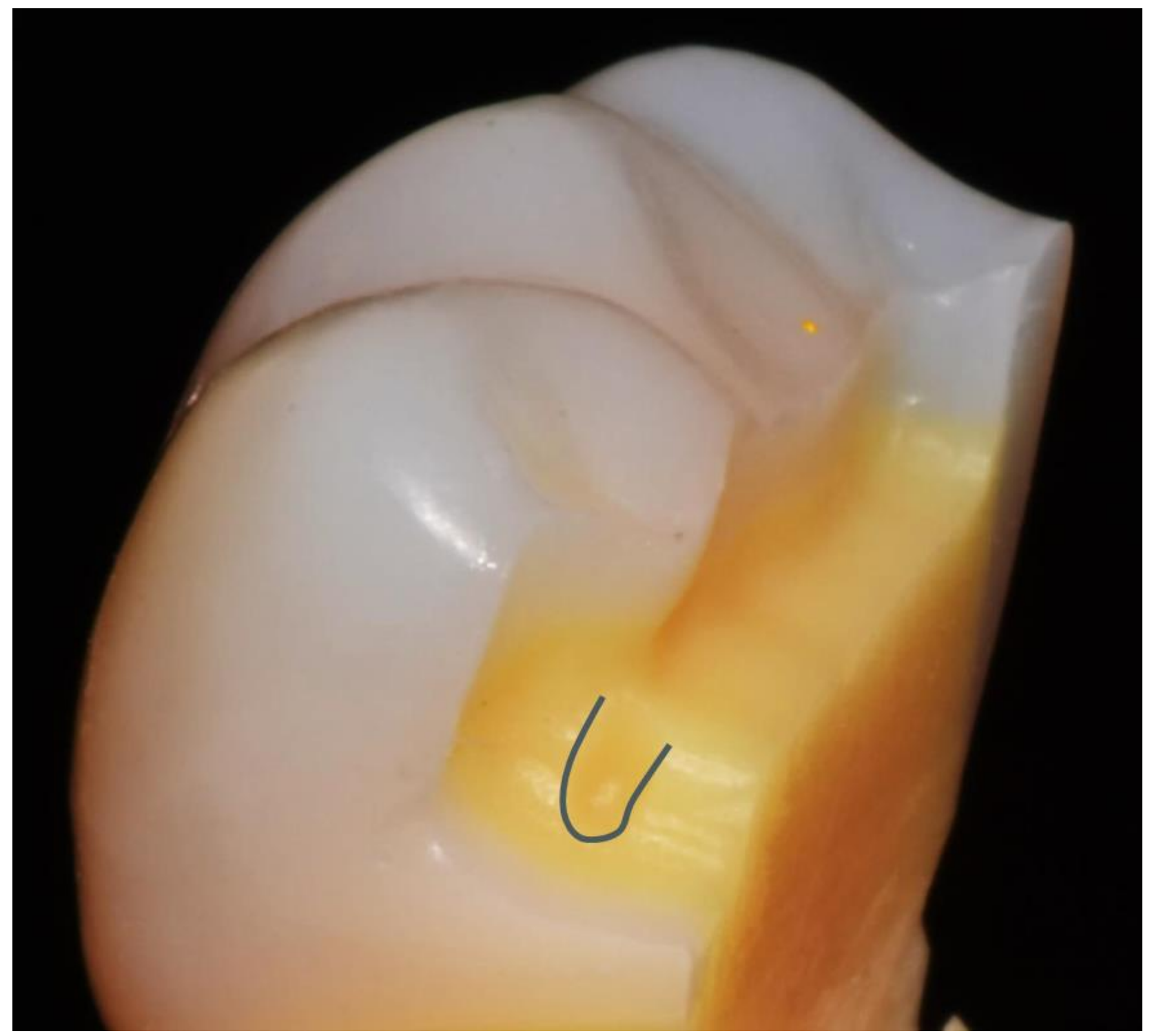

FIGURES 3.4- 3D model demonstrating clinically unacceptable retention groove placement in the axial wall of a preparation with ideal axial wall depth. 


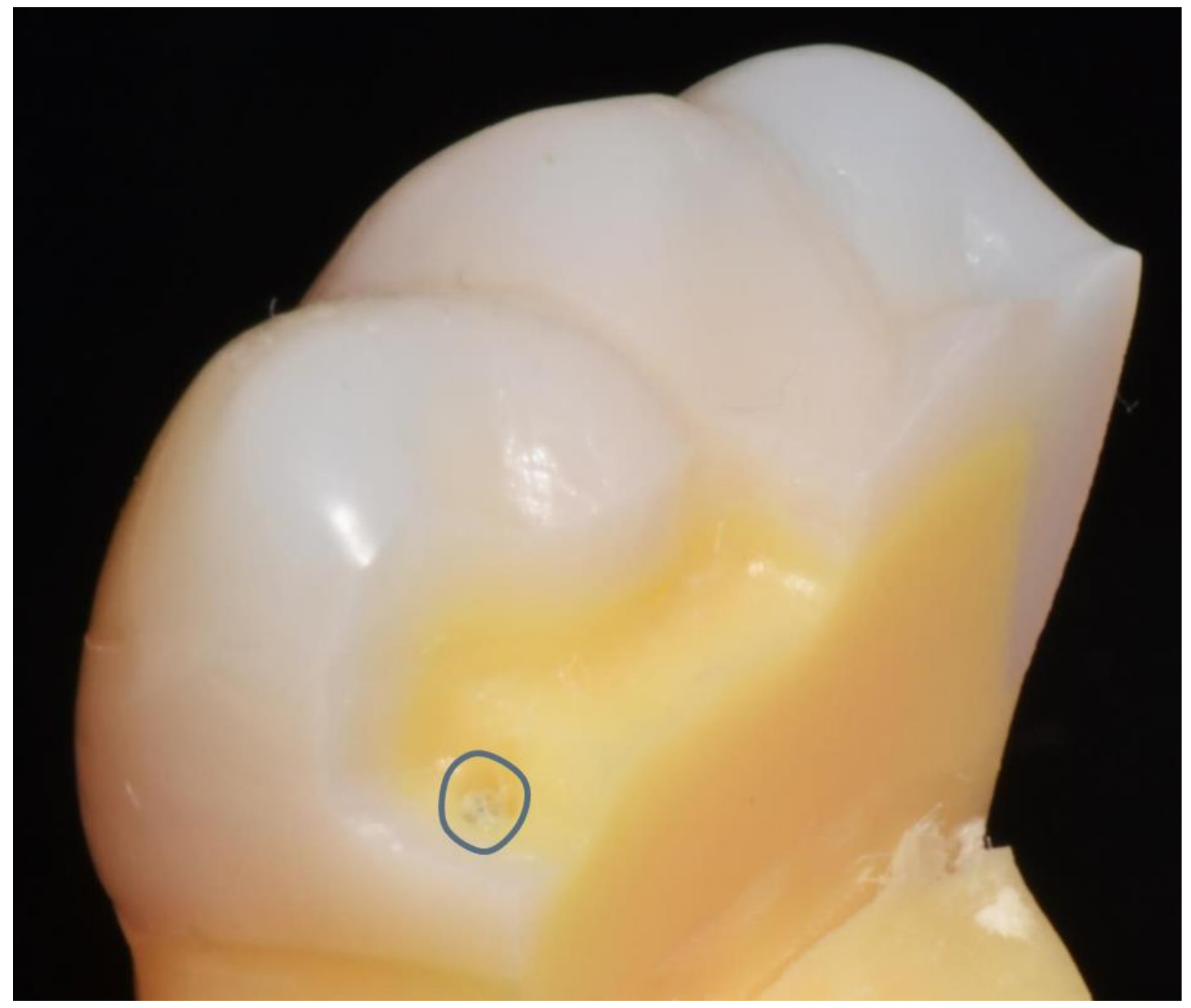

FIGURES 3.5- 3D model demonstrating clinically unacceptable retention groove placement in the gingival wall of a preparation with ideal axial wall depth . 


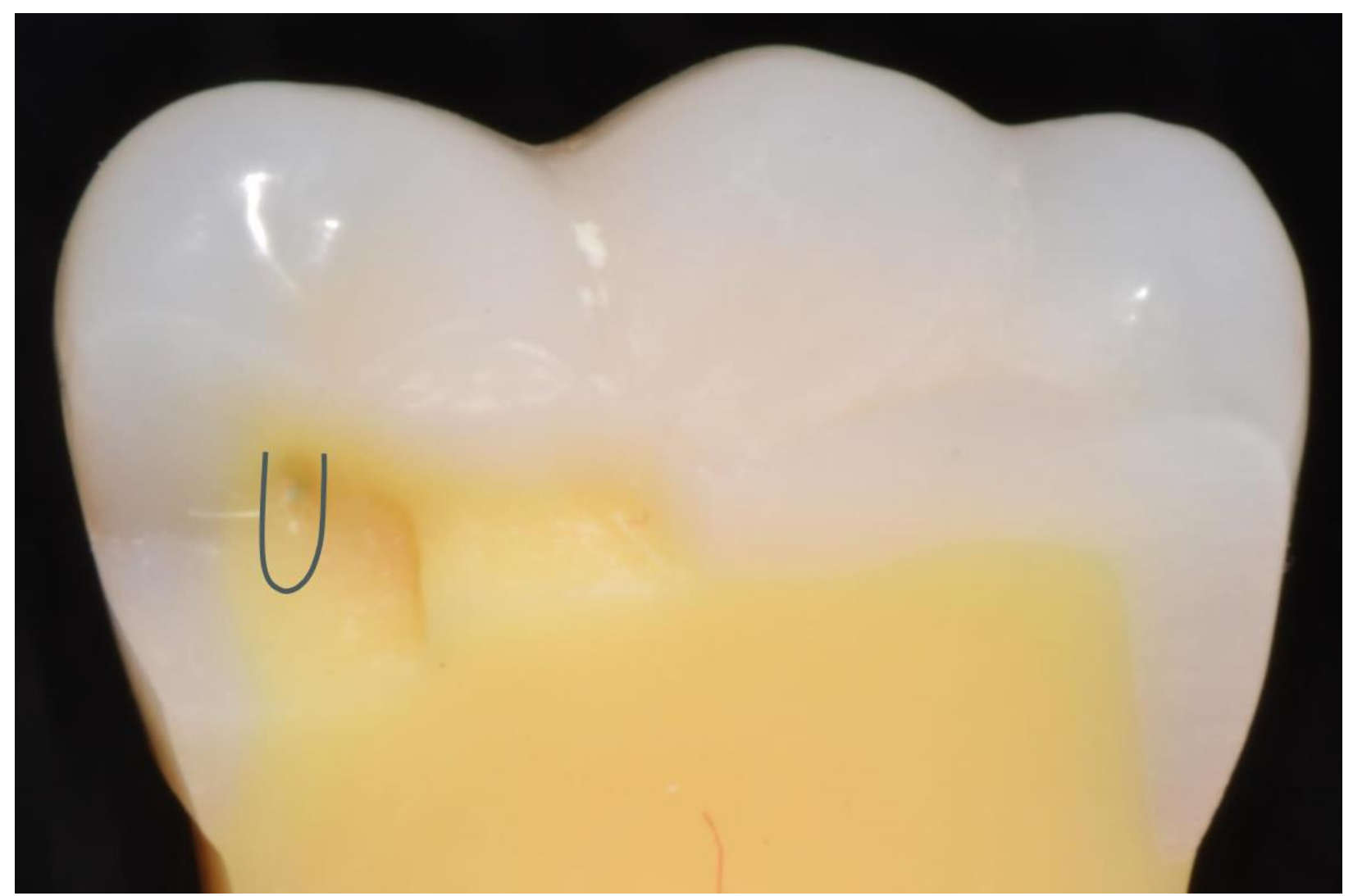

FIGURES 3.6- 3D model demonstrating clinically acceptable retention groove placement $\sim 0.2 \mathrm{~mm}$ internal to the DEJ in the facial dentin wall of a preparation with deep axial wall depth. 


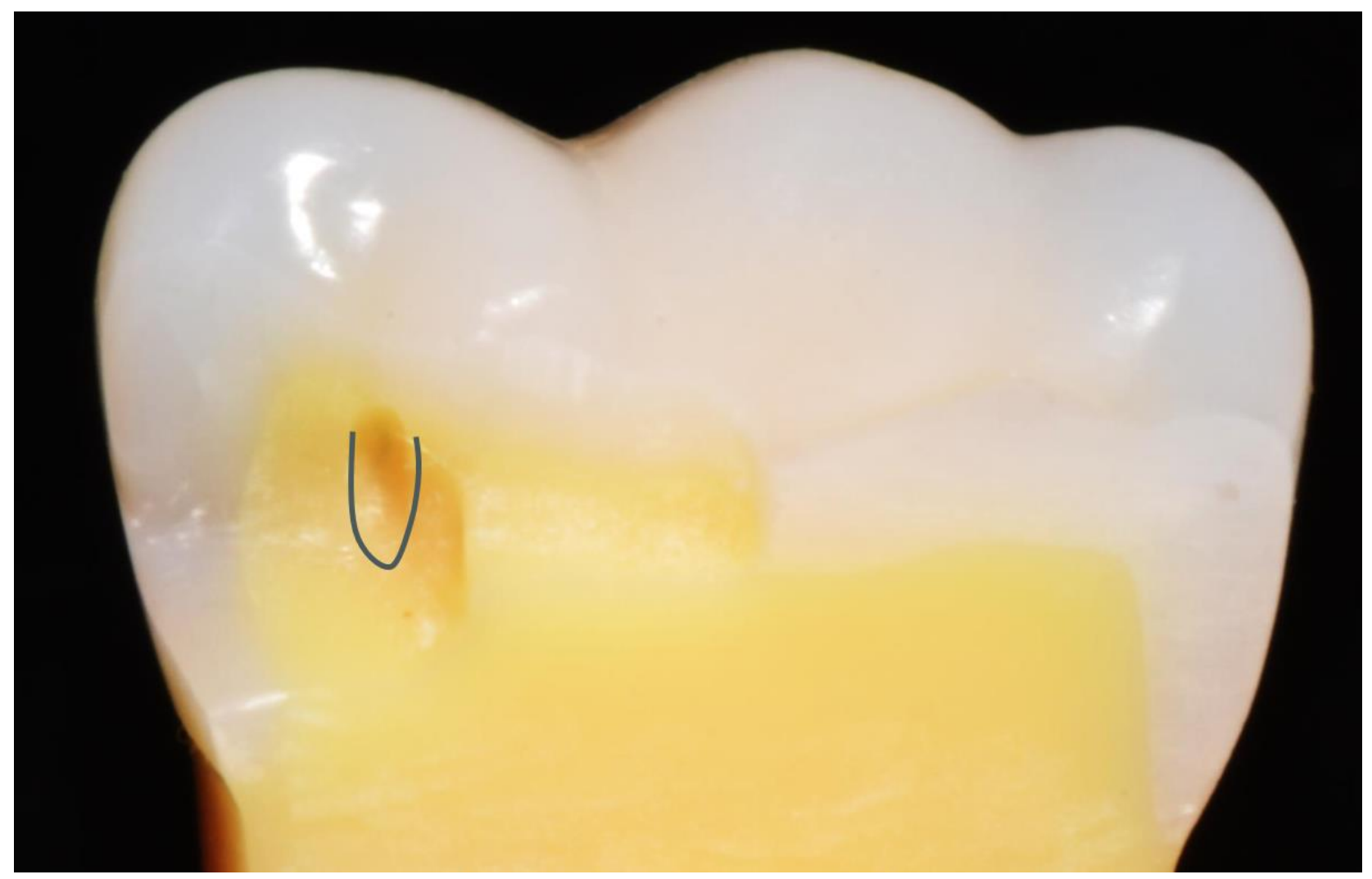

FIGURES 3.7- 3D model demonstrating clinically unacceptable retention groove placement in the line angle of the facial and axial walls of a preparation with deep axial wall depth. 

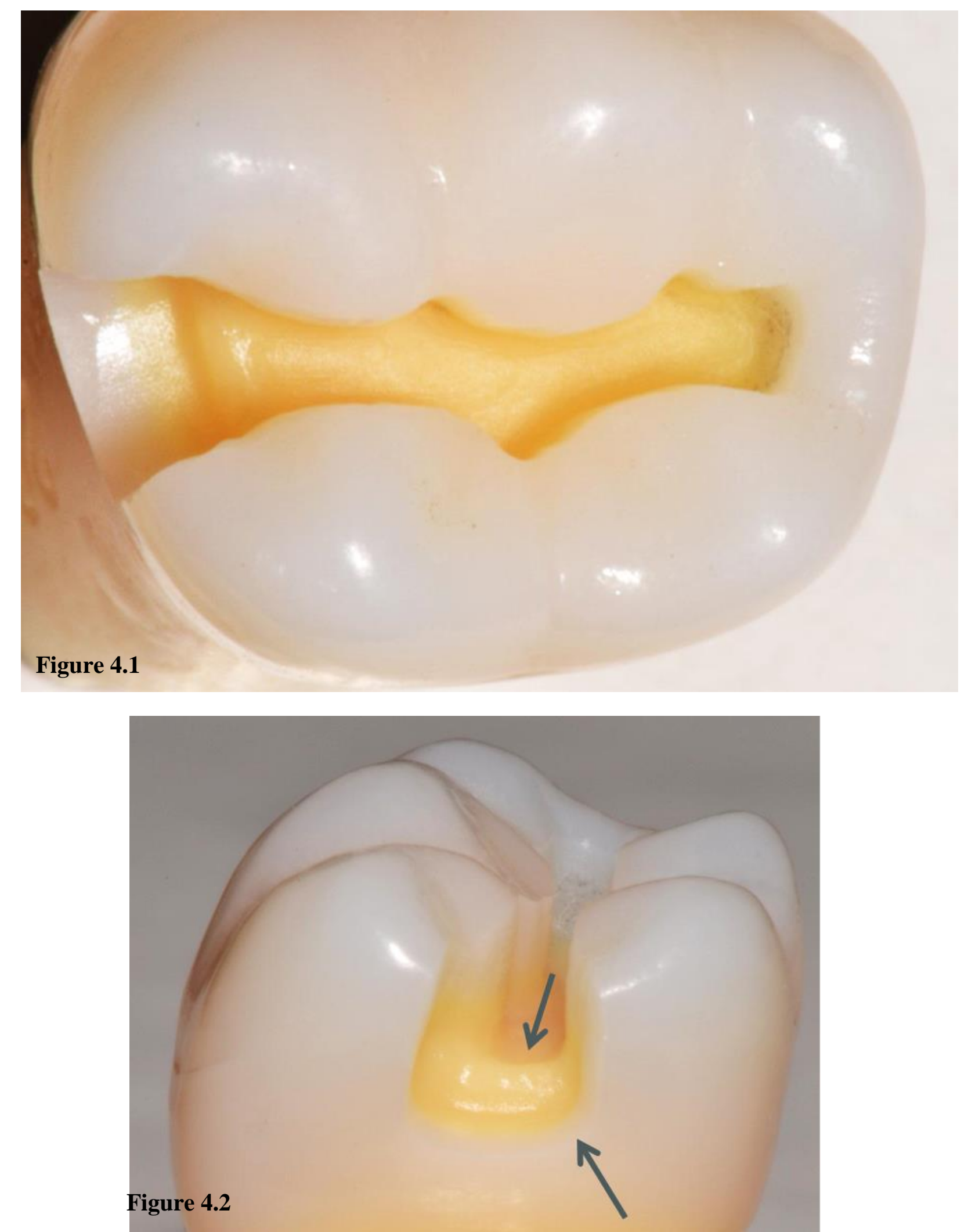

FIGURES $4.1 \& 4.2$ - 3D model demonstrating clinically acceptable preparation finish of smooth walls and gentle transitions. 

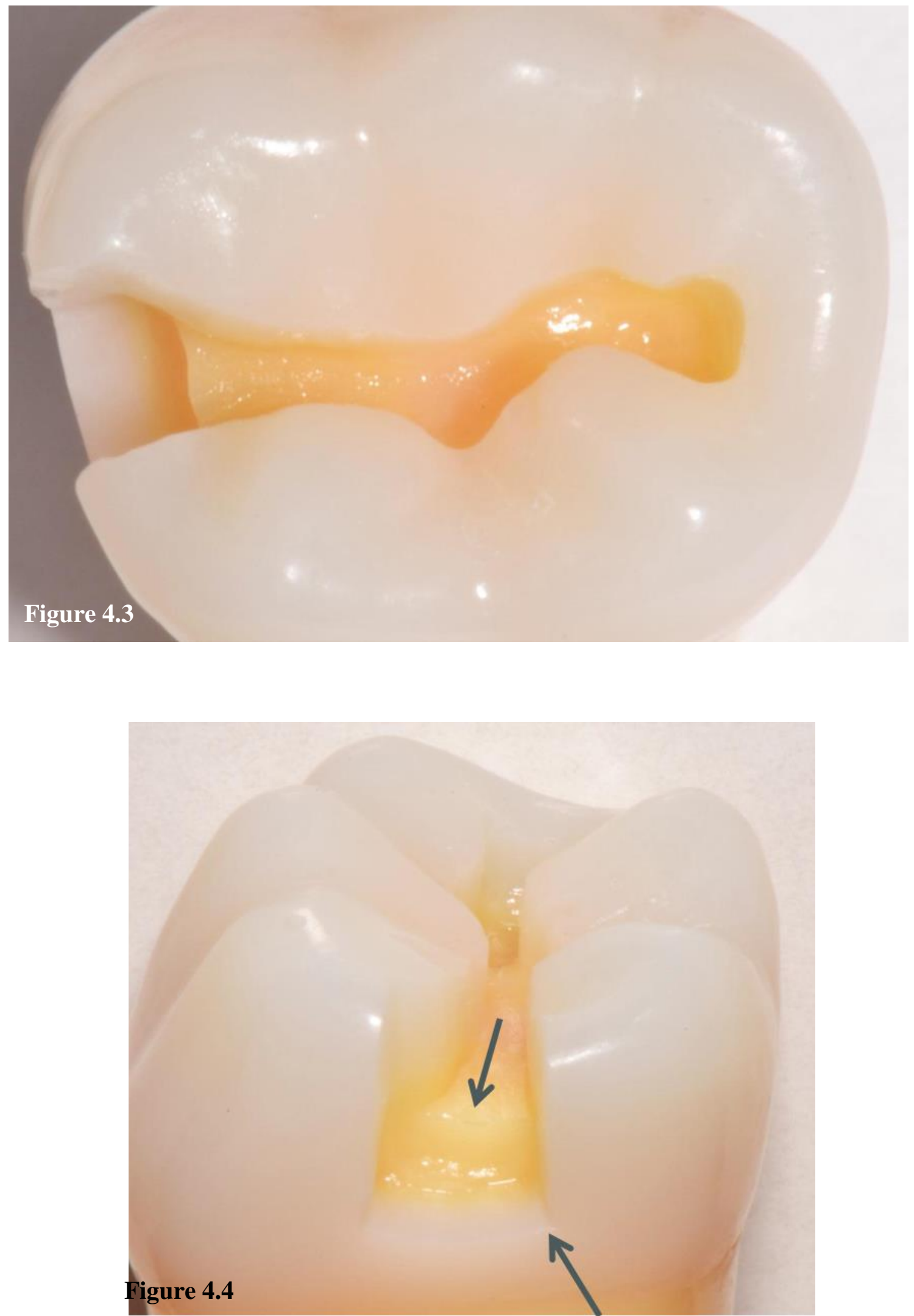

FIGURES $4.3 \& 4.4$ - 3D model demonstrating clinically unacceptable preparation finish of smooth walls and abrupt transitions. 

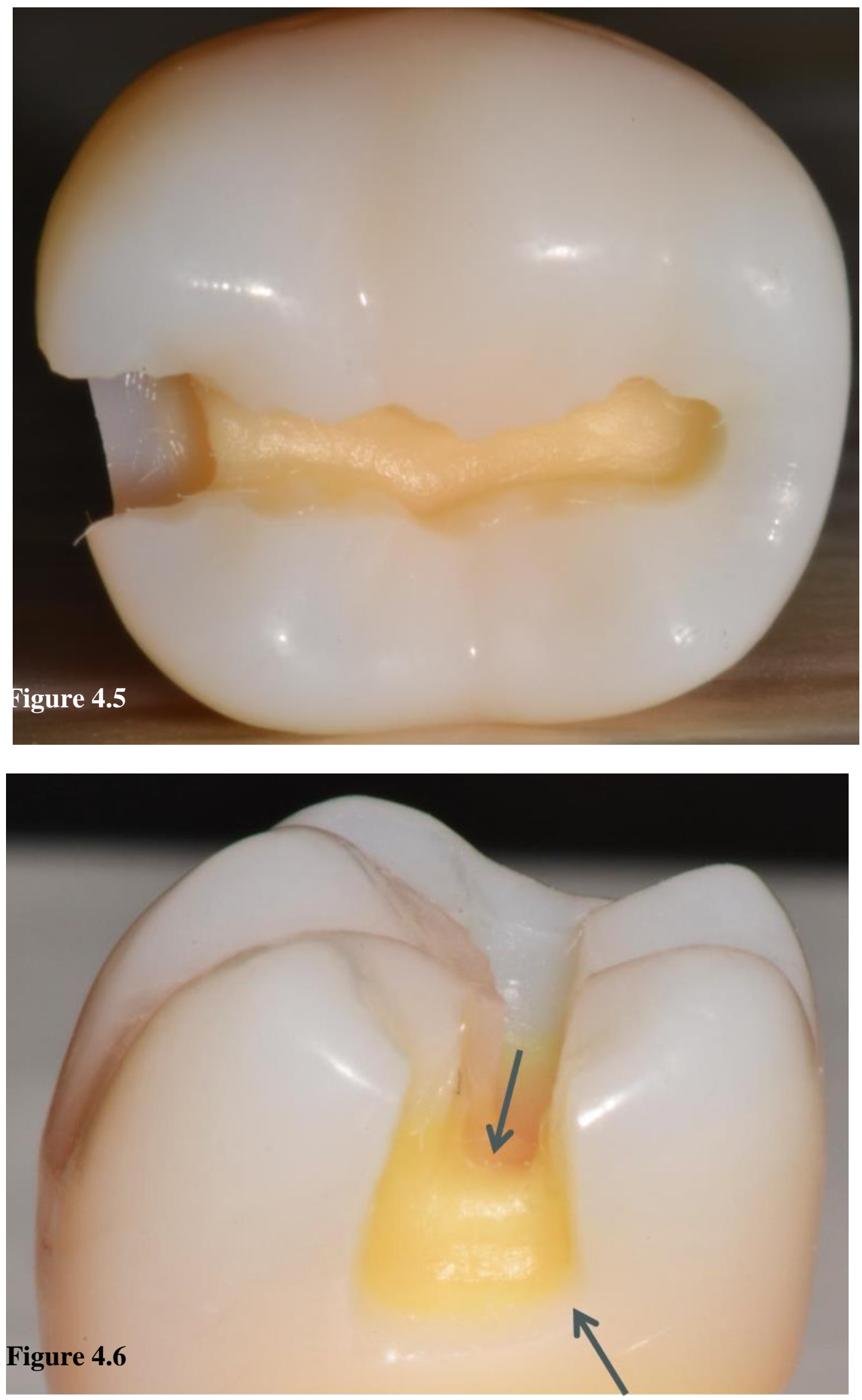

FIGURES $4.5 \&$ 4.6 - 3D model demonstrating clinically unacceptable preparation finish of rough walls and gentle transitions. 

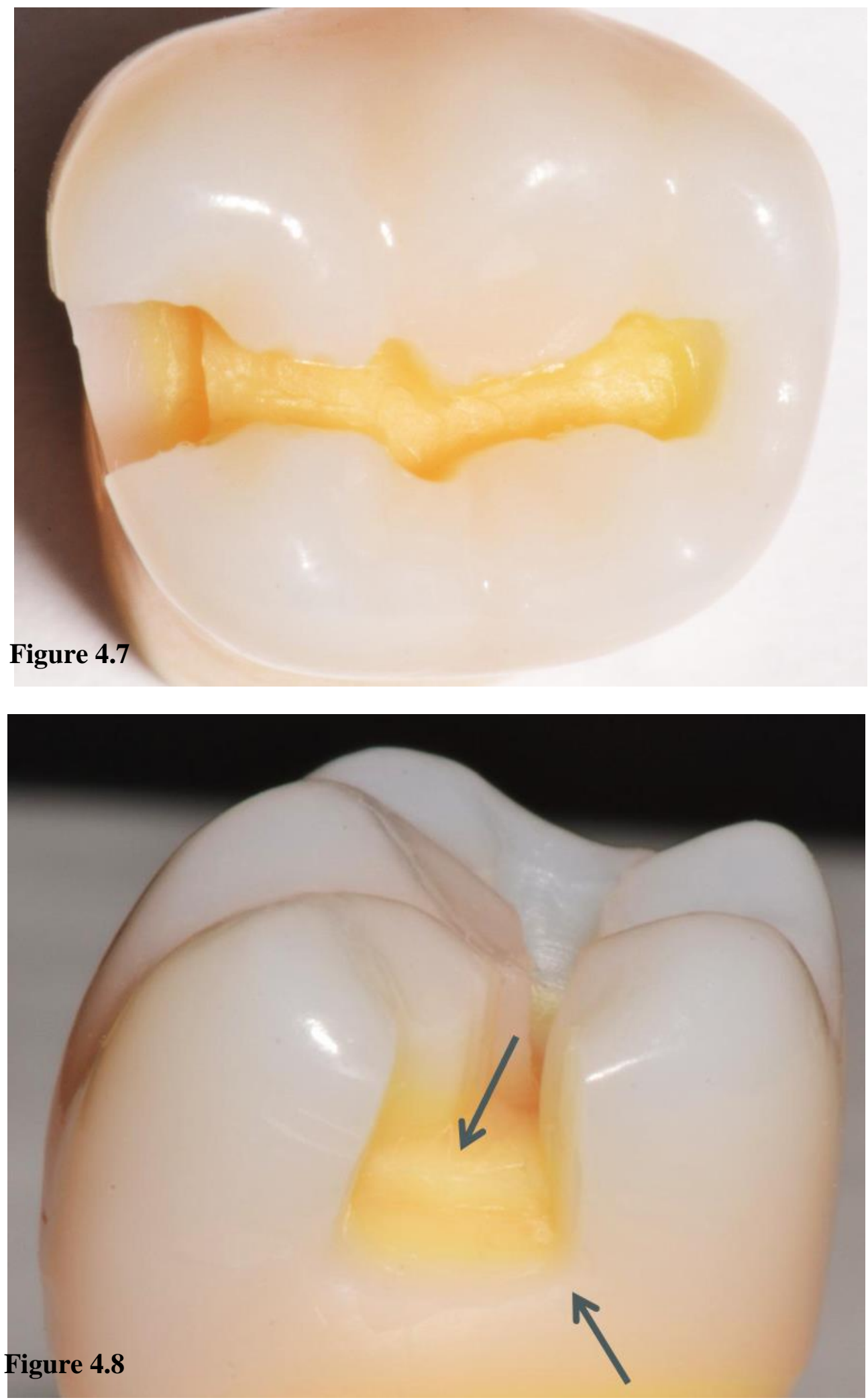

FIGURES $4.7 \& 4.8$ - 3D model demonstrating clinically unacceptable preparation finish of rough walls and abrupt transitions. 


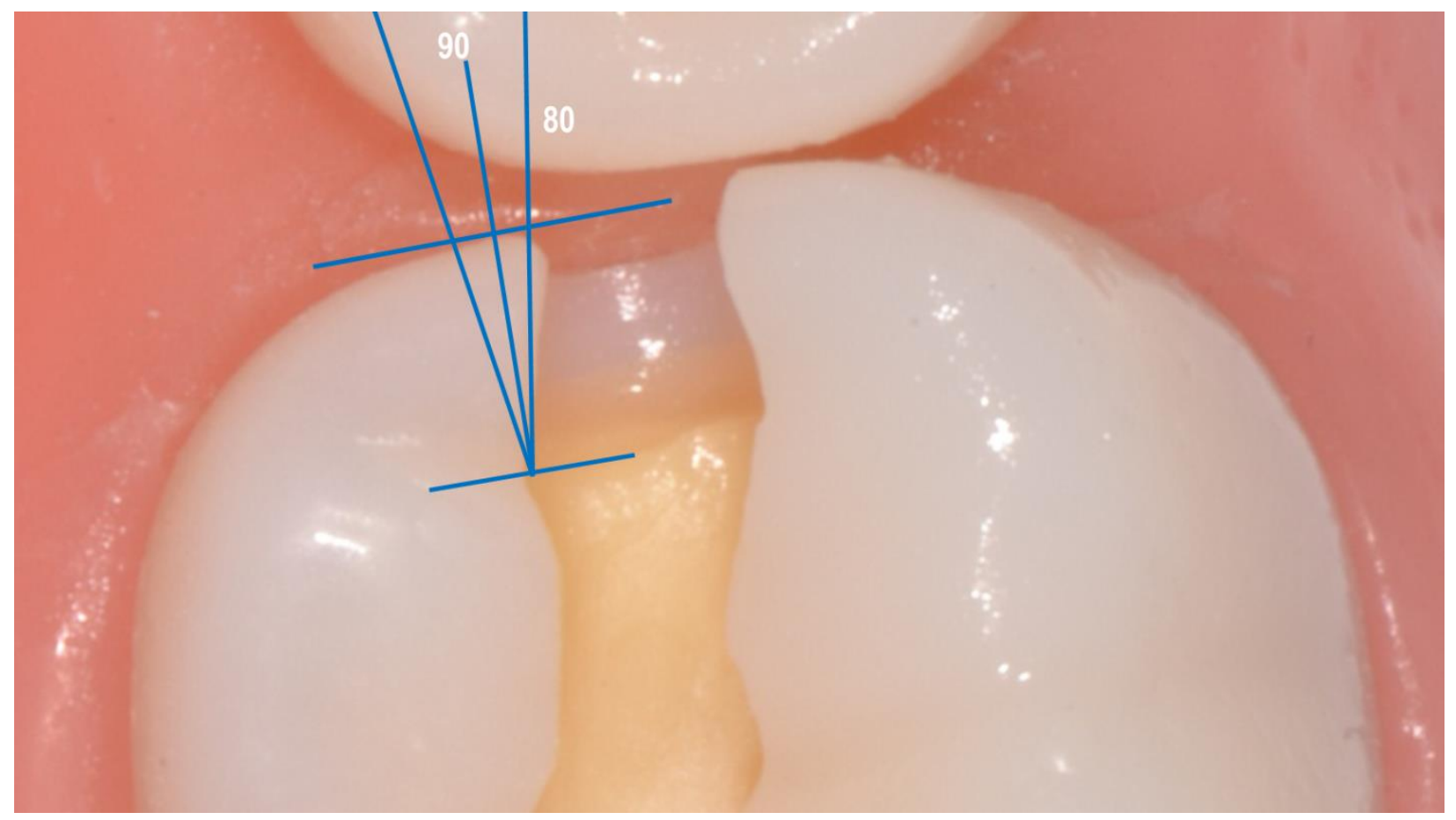

FIGURE 5.1- Image of the 3D model with a superimposed protractor that demonstrates clinically unacceptable preparation wall orientation of $<80^{\circ}$. 


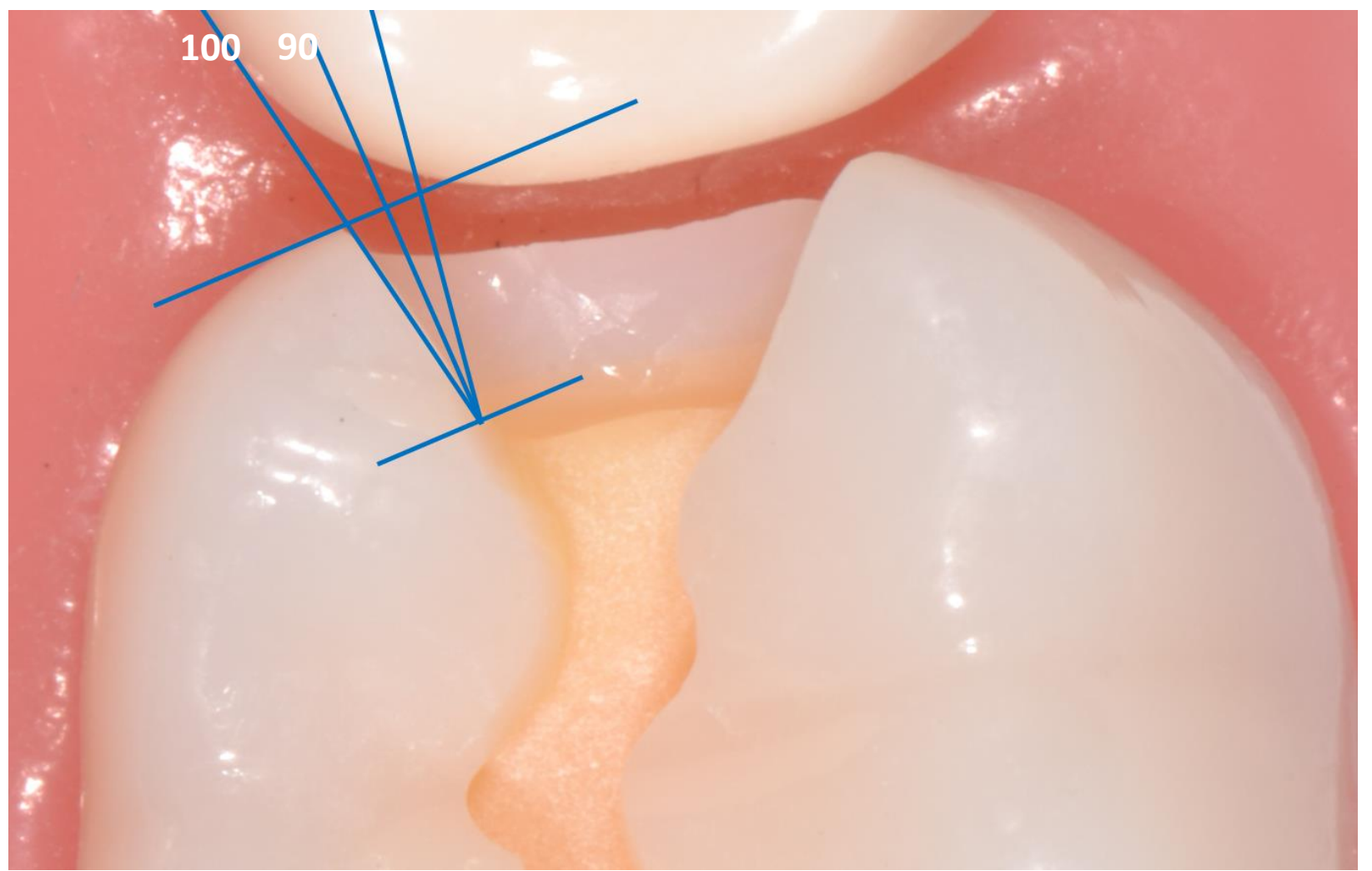

FIGURE 5.2- Image of the 3D model with a superimposed protractor that demonstrates clinically unacceptable preparation wall orientation of $>100^{0}$. 


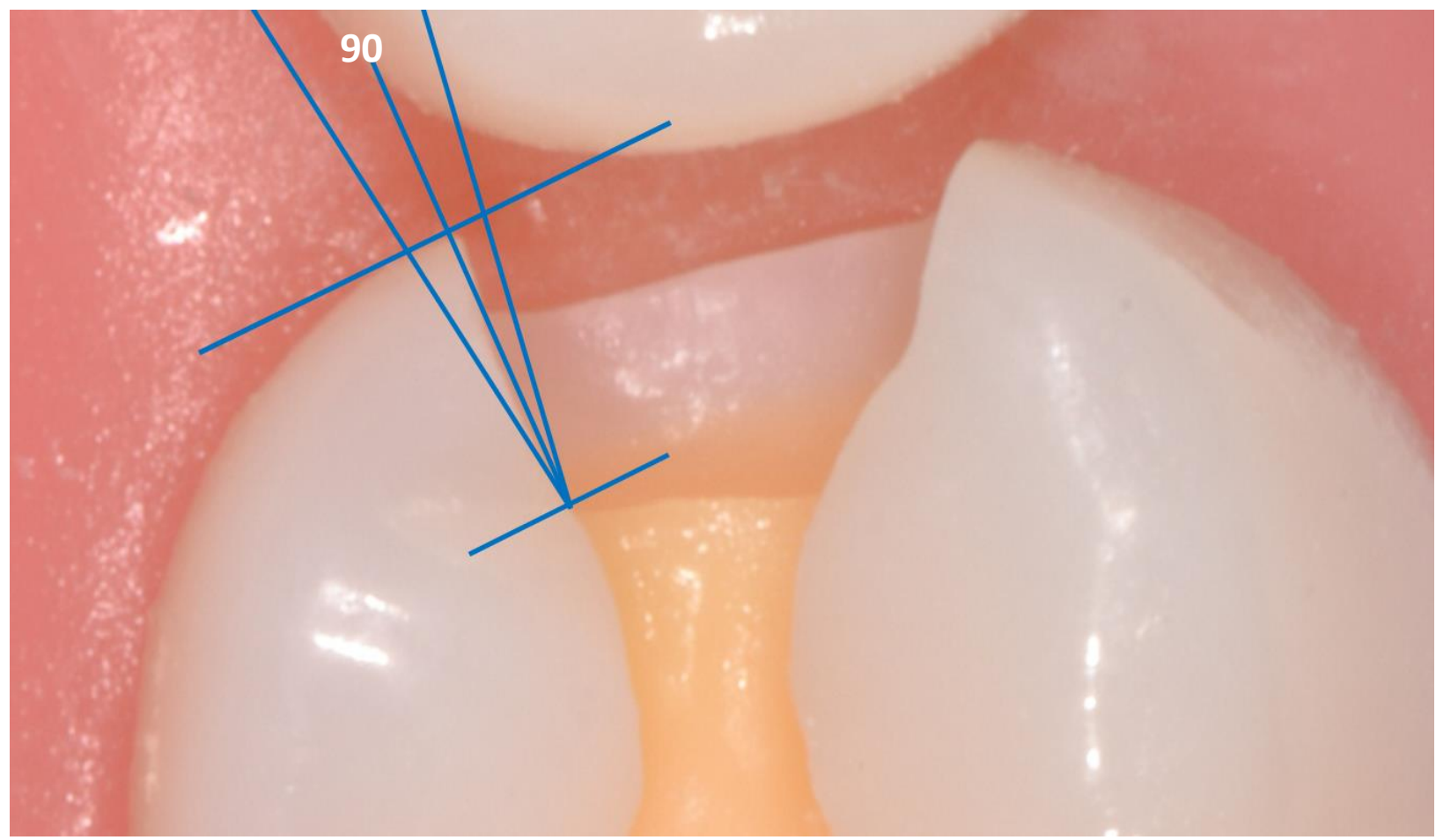

FIGURE 5.3- Image of the 3D model with a superimposed protractor that demonstrates clinically acceptable preparation wall orientation of approximately $90^{\circ}$. 
TABLE 3 - Class II amalgam procedure assessment rubric that was used to define the level of student performance and associated point values for each component

\begin{tabular}{|c|c|c|}
\hline $\begin{array}{l}\text { PREPARATION } \\
\text { COMPONENTS }\end{array}$ & $\begin{array}{l}\text { SPECIFIC CRITERIA FOR } \\
\text { EACH COMPONENT }\end{array}$ & $\begin{array}{c}\text { POINT VALUES FOR } \\
\text { EACH CRITERIA } \\
\text { (Clinically acceptable-CA) } \\
\text { (Clinically unacceptable-CU) }\end{array}$ \\
\hline \multicolumn{3}{|l|}{$\begin{array}{l}\text { EXTERNAL } \\
\text { OUTLINE }\end{array}$} \\
\hline DEJ Caries & $\begin{array}{l}\text { Complete removal at the } \mathrm{DEJ} \\
\text { Incomplete removal at the } \mathrm{DEJ}\end{array}$ & $\begin{array}{l}\mathbf{1}(\mathrm{CA}) \\
\mathbf{0}(\mathrm{CU})\end{array}$ \\
\hline Isthmus Width & $\begin{array}{l}\text { Less than } 1 \mathrm{~mm} \\
\text { Between } 1 \mathrm{~mm} \text { and } 1 / 3 \text { of } \\
\text { intercuspal distance } \\
\text { Between } 1 / 3 \text { and } 1 / 2 \text { of } \\
\text { intercuspal distance } \\
\text { Greater than } 1 / 2 \text { of intercuspal } \\
\text { distance }\end{array}$ & $\begin{array}{l}1(\mathrm{CU}) \\
3 \mathrm{CA}) \\
2(\mathrm{CA}) \\
0(\mathrm{CU})\end{array}$ \\
\hline $\begin{array}{l}\text { Proximal Contact } \\
\text { Clearance }\end{array}$ & $\begin{array}{l}\text { No Clearance } \\
\text { Open up to } 0.5 \mathrm{~mm} \text { in all } \\
\text { directions } \\
\text { Open between } 0.5 \text { and } 0.75 \\
\text { mm in any direction } \\
\text { Open more than } 0.75 \mathrm{~mm} \text { in } \\
\text { any direction }\end{array}$ & $\begin{array}{l}1 \text { (CU) } \\
3 \text { (CA) } \\
2 \text { (CA) } \\
0 \text { (CU) }\end{array}$ \\
\hline $\begin{array}{l}\text { Adjacent Tooth } \\
\text { Damage }\end{array}$ & $\begin{array}{l}\text { No damage } \\
\text { Requires re-contouring } \\
\text { Requires restoration }\end{array}$ & $\begin{array}{l}2(\mathrm{CA}) \\
1(\mathrm{CU}) \\
0(\mathrm{CU})\end{array}$ \\
\hline \multicolumn{3}{|l|}{ INTERNAL FORM } \\
\hline Enamel Present & $\begin{array}{l}\text { None } \\
\text { Less than or equal to } 50 \% \text { of } \\
\text { preparation } \\
\text { Greater than } 50 \% \text { of } \\
\text { preparation }\end{array}$ & $\begin{array}{l}2 \text { (CA) } \\
1(\mathrm{CU}) \\
0(\mathrm{CU})\end{array}$ \\
\hline $\begin{array}{l}\text { Primary Pulpal/Axial } \\
\text { Wall }\end{array}$ & $\begin{array}{l}\text { Less than or equal to } 0.5 \mathrm{~mm} \\
\text { internal to DEJ } \\
0.5 \text { - } 1.5 \mathrm{~mm} \text { internal to DEJ } \\
2.0 \text { - } 2.5 \mathrm{~mm} \text { internal to DEJ } \\
\text { Greater than } 2.5 \mathrm{~mm} \text { internal }\end{array}$ & $\begin{array}{l}3 \text { (CA) } \\
2 \text { (CA) } \\
1 \text { (CU) } \\
0 \text { (CU) }\end{array}$ \\
\hline
\end{tabular}




\begin{tabular}{|c|c|c|}
\hline & to DEJ & \\
\hline Caries Removal & $\begin{array}{l}\text { Incomplete } \\
\text { Complete } \\
\text { Complete with excessive dentin } \\
\text { removal }\end{array}$ & $\begin{array}{l}\mathbf{0}(\mathrm{CU}) \\
2(\mathrm{CA}) \\
1(\mathrm{CU})\end{array}$ \\
\hline \multicolumn{3}{|l|}{ RETENTION FORM } \\
\hline External Walls & $\begin{array}{l}\text { Occlusal convergence with } \\
20^{\circ} \text { cavosurface margin } \\
\text { Excessive occlusal convergence } \\
\text { with }<90^{\circ} \text { cavosurface margin } \\
\text { External walls parallel } \\
\text { External walls diverge } \\
\text { occlusally }\end{array}$ & $\begin{array}{l}3(\mathrm{CA}) \\
2(\mathrm{CA}) \\
1(\mathrm{CU}) \\
0(\mathrm{CU})\end{array}$ \\
\hline $\begin{array}{l}\text { Retention Groove } \\
\text { Placement }\end{array}$ & $\begin{array}{l}\text { Undermined enamel } \\
\approx 0.2 \mathrm{~mm} \text { internal to } \mathrm{DEJ} \\
\text { Between } 0.2 \mathrm{~mm} \text { and } 1 \mathrm{~mm} \\
\text { internal to } \mathrm{DEJ} \\
\text { Greater than } 1 \mathrm{~mm} \text { internal to } \\
\text { DEJ } \\
\text { Not Visible }\end{array}$ & $\begin{array}{l}0(\mathrm{CU}) \\
3(\mathrm{CA}) \\
2(\mathrm{CA}) \\
1(\mathrm{CU}) \\
-1(\mathrm{CU})\end{array}$ \\
\hline $\begin{array}{l}\text { Retention Groove } \\
\text { Depth }\end{array}$ & $\begin{array}{l}\text { Undetectable } \\
\text { Between } 0.1 \mathrm{~mm} \text { and } 0.5 \mathrm{~mm} \\
\text { Greater than } 0.5 \mathrm{~mm}\end{array}$ & $\begin{array}{l}0(\mathrm{CU}) \\
2(\mathrm{CA}) \\
1(\mathrm{CU})\end{array}$ \\
\hline \multicolumn{3}{|l|}{$\begin{array}{l}\text { PREPARATION } \\
\text { FINISH }\end{array}$} \\
\hline Preparation Walls & $\begin{array}{l}\text { Smooth, gentle transitions } \\
\text { Rough, abrupt transitions }\end{array}$ & $\begin{array}{l}\text { (CA) } \\
\mathbf{0}(\mathbf{C U}) \\
\end{array}$ \\
\hline Preparation Margins & $\begin{array}{l}\text { Unsupported enamel }\left(<\mathbf{8 0}^{\circ}\right) \\
\text { Supported enamel }\left(\mathbf{9 0}^{\circ}\right) \\
\text { Enamel margin }\left(>\mathbf{1 0 0}^{\circ}\right)\end{array}$ & $\begin{array}{l}0(\mathrm{CU}) \\
2(\mathrm{CA}) \\
1(\mathrm{CU})\end{array}$ \\
\hline Preparation Toilet & $\begin{array}{l}\text { Debris present } \\
\text { Clean }\end{array}$ & $\begin{array}{l}0(\mathrm{CU}) \\
1(\mathrm{CA})\end{array}$ \\
\hline
\end{tabular}




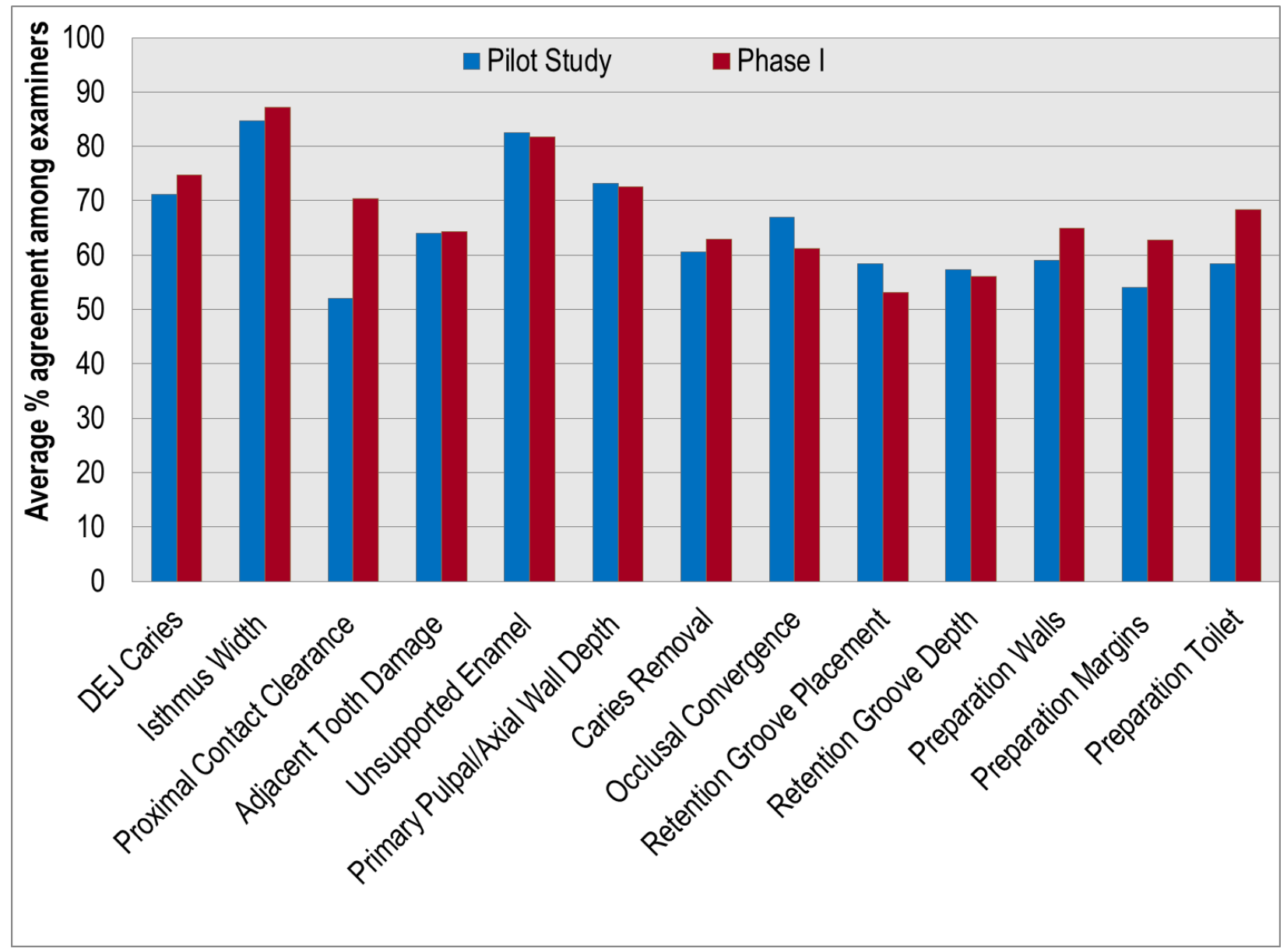

FIGURE 6- Average percentage agreement after assessment of 13 procedural components of Class II cavity preparations among examiners at Pilot and Phase I. 
TABLE 4 - Average percent agreement (mean +/- sd) and 95\% CI for assessment of components of Class II cavity preparation during Phase I

\begin{tabular}{|l|c|c|c|}
\hline $\begin{array}{c}\text { COMPONENTS OF CLASS II CAVITY } \\
\text { PREPARATION }\end{array}$ & MEAN & STD DEV & $\begin{array}{c}\text { 95\% CI - PHASE I } \\
\text { (LOWER, UPPER) }\end{array}$ \\
\hline DEJ Caries & 74.67 & 15.15 & $(68.79,80.54)$ \\
Isthmus Width & 87.17 & 8.22 & $(83.98,90.35)$ \\
Proximal Contact Clearance & 70.43 & 6.67 & $(67.84,73.02)$ \\
Adjacent Tooth Damage & 64.29 & 11.64 & $(59.78,68.81)$ \\
Enamel Present & 81.81 & 29.25 & $(70.47,93.15)$ \\
Primary Pulpal/Axial Wall & 72.55 & 14.52 & $(66.92,78.18)$ \\
Caries Removal & 62.95 & 21.04 & $(54.79,71.11)$ \\
External Walls & 61.17 & 23.16 & $(52.19,70.15)$ \\
Retentive Groove Placement & 53.06 & 17.82 & $(46.15,59.97)$ \\
Retention Groove Depth & 56.03 & 12.90 & $(51.03,61.03)$ \\
Preparation Walls & 64.89 & 18.66 & $(54.16,68.62)$ \\
Preparation Margins & 62.73 & 11.84 & $(58.13,67.32)$ \\
Preparation Toilet & 68.31 & 11.62 & $(63.80,72.81)$ \\
\hline
\end{tabular}


TABLE 5 - Average percentage intra examiner agreement for each examiner when comparing the results from Pilot Study to Phase I

\begin{tabular}{|c|c|c|}
\hline $\begin{array}{c}\text { EXAMINERS: PILOT STUDY - } \\
\text { PHASE I }\end{array}$ & $\begin{array}{c}\text { AVERAGE INTRA- } \\
\text { EXAMINER } \\
\text { AGREEMENT (\%) }\end{array}$ & AVERAGE KAPPA \\
\hline Examiner A Pilot - Phase I & 68 & 0.32 \\
\hline Examiner B Pilot -Phase I & 68 & 0.33 \\
\hline Examiner C Pilot -Phase I & 74 & 0.50 \\
\hline Examiner D Pilot -Phase I & 77 & 0.45 \\
\hline Examiner E Pilot -Phase I & 72 & 0.49 \\
\hline Examiner F Pilot -Phase I & 83 & 0.58 \\
\hline Examiner G Pilot -Phase I & 72 & 0.41 \\
\hline Examiner H Pilot -Phase I & 80 & 0.56 \\
\hline
\end{tabular}




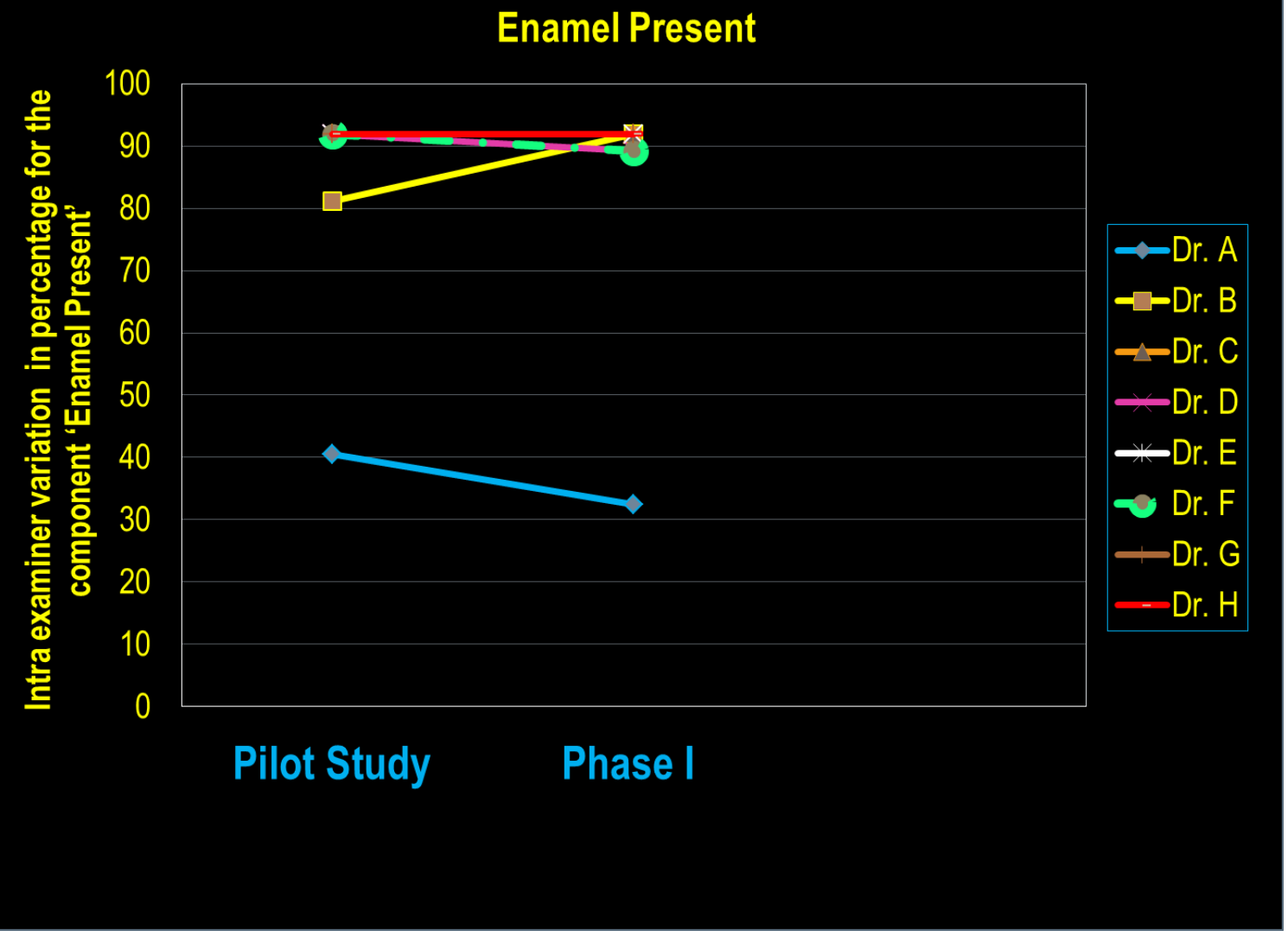

FIGURE 7 - The component 'Enamel Present' had the lowest intraexaminer variation from Pilot study to Phase I 


\section{Proximal Contact Clearance}

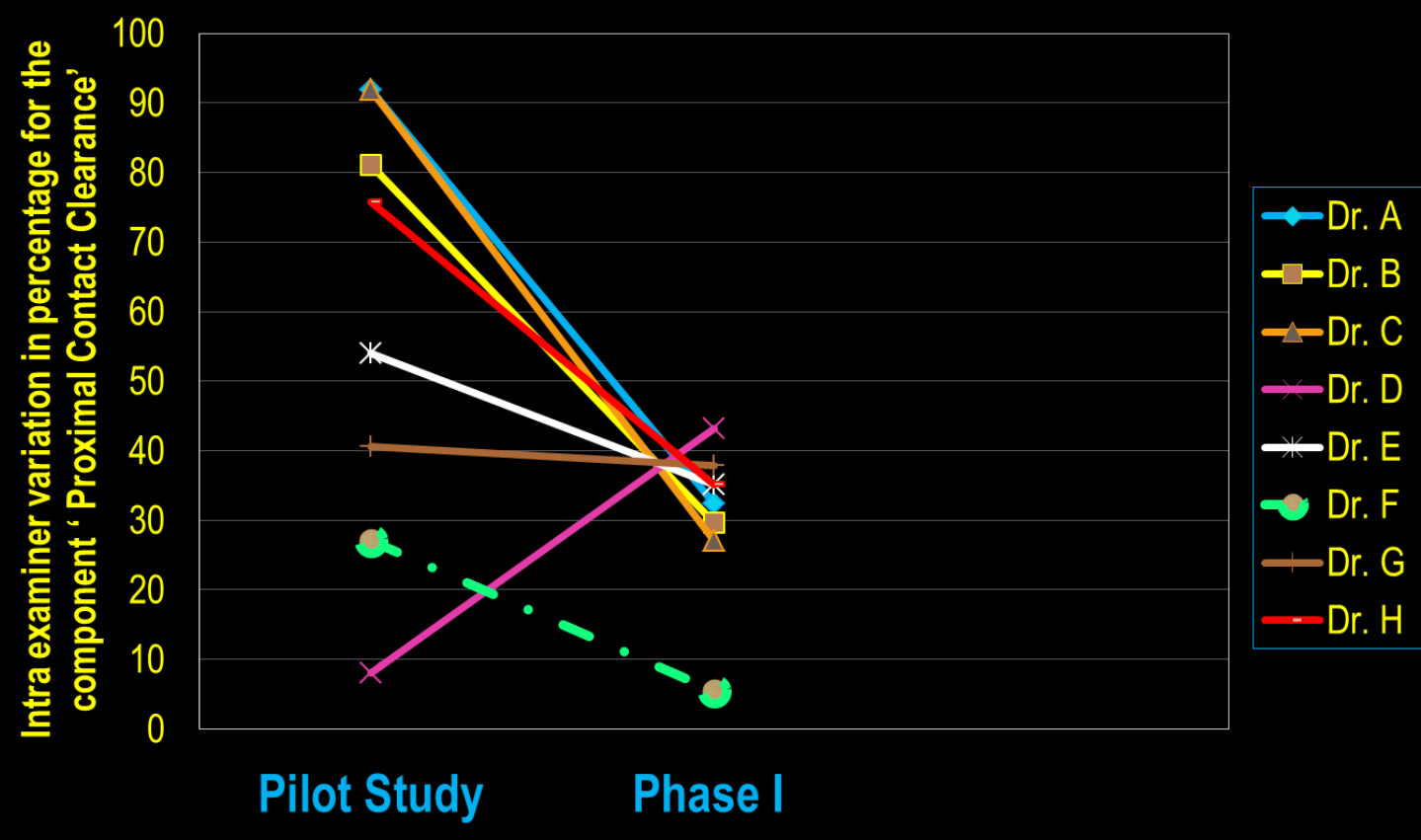

FIGURE 8 - The component 'Proximal Contact Clearance' had the highest intraexaminer variation from Pilot study to Phase I 
TABLE 6- The level of intraexaminer variation (\%) for all 13 components of Class II cavity preparation for each examiner when comparing Pilot study to Phase I

\begin{tabular}{|c|c|c|c|c|c|c|c|c|c|c|c|}
\hline \multirow{16}{*}{ 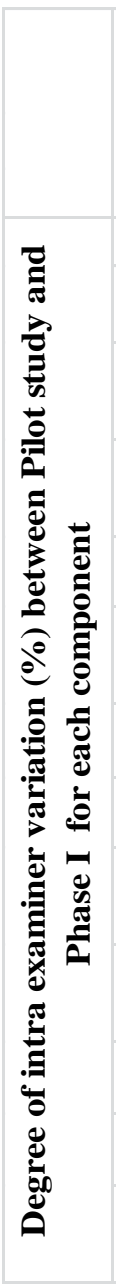 } & \multirow{3}{*}{$\begin{array}{l}\text { Components of Class } \\
\text { II cavity preparation }\end{array}$} & \multicolumn{8}{|c|}{$\begin{array}{c}\text { Degree of intra examiner variation }(\%) \text { between Pilot study and } \\
\text { Phase I for each examiner }\end{array}$} & \multirow{3}{*}{$\begin{array}{c}\text { Mean } \\
(\%)\end{array}$} & \multirow{3}{*}{ Std Dev } \\
\hline & & \multicolumn{8}{|c|}{ Examiners A through $\mathrm{H}$} & & \\
\hline & & A & B & C & D & E & $\mathbf{F}$ & G & $\mathbf{H}$ & & \\
\hline & DEJ Caries & 0.0 & 21.6 & 2.7 & 10.8 & 62.2 & 5.4 & 29.7 & 8.1 & 17.6 & 19 \\
\hline & Isthmus Width & 10.8 & 5.4 & 10.8 & 13.5 & 2.7 & 8.1 & 18.9 & 0.0 & 8.8 & 6 \\
\hline & $\begin{array}{l}\text { Proximal Contact } \\
\text { Clearance }\end{array}$ & 59.5 & 51.4 & 64.9 & 35.1 & 18.9 & 21.6 & 2.7 & 40.5 & 36.8 & 20 \\
\hline & $\begin{array}{l}\text { Adjacent Tooth } \\
\text { Damage }\end{array}$ & 2.7 & 29.7 & 0.0 & 5.4 & 8.1 & 10.8 & 5.4 & 0.0 & 7.8 & 9 \\
\hline & Enamel Present & 8.1 & 10.8 & 0.0 & 2.7 & 0.0 & 2.7 & 0.0 & 0.0 & 3.0 & 4 \\
\hline & $\begin{array}{l}\text { Primary Pulpal/Axial } \\
\text { Wall }\end{array}$ & 5.4 & 21.6 & 43.3 & 16.2 & 18.9 & 0.0 & 13.5 & 5.4 & 15.5 & 13 \\
\hline & Caries Removal & 18.9 & 5.4 & 0.0 & 5.4 & 13.5 & 18.9 & 8.1 & 2.7 & 9.1 & 7 \\
\hline & External Walls & 16.2 & 5.4 & 13.5 & 2.7 & 18.9 & 8.1 & 62.2 & 13.5 & 17.6 & 18 \\
\hline & $\begin{array}{l}\text { Retentive Groove } \\
\text { Placement }\end{array}$ & 10.8 & 18.9 & 2.7 & 27.0 & 18.9 & 13.5 & 13.5 & 35.1 & 17.6 & 9 \\
\hline & $\begin{array}{l}\text { Retention Groove } \\
\text { Depth }\end{array}$ & 5.4 & 21.6 & 29.7 & 29.7 & 2.7 & 2.7 & 13.5 & 13.5 & 14.9 & 10 \\
\hline & Preparation Walls & 18.9 & 16.2 & 21.6 & 27.0 & 16.2 & 8.1 & 45.9 & 48.7 & 25.3 & 14 \\
\hline & Preparation Margins & 13.5 & 13.5 & 35.1 & 8.1 & 27.0 & 5.4 & 43.2 & 16.2 & 20.3 & 13 \\
\hline & Preparation Toilet & 29.7 & 16.2 & 37.8 & 16.2 & 8.1 & 5.4 & 2.7 & 0.0 & 14.5 & 13 \\
\hline
\end{tabular}




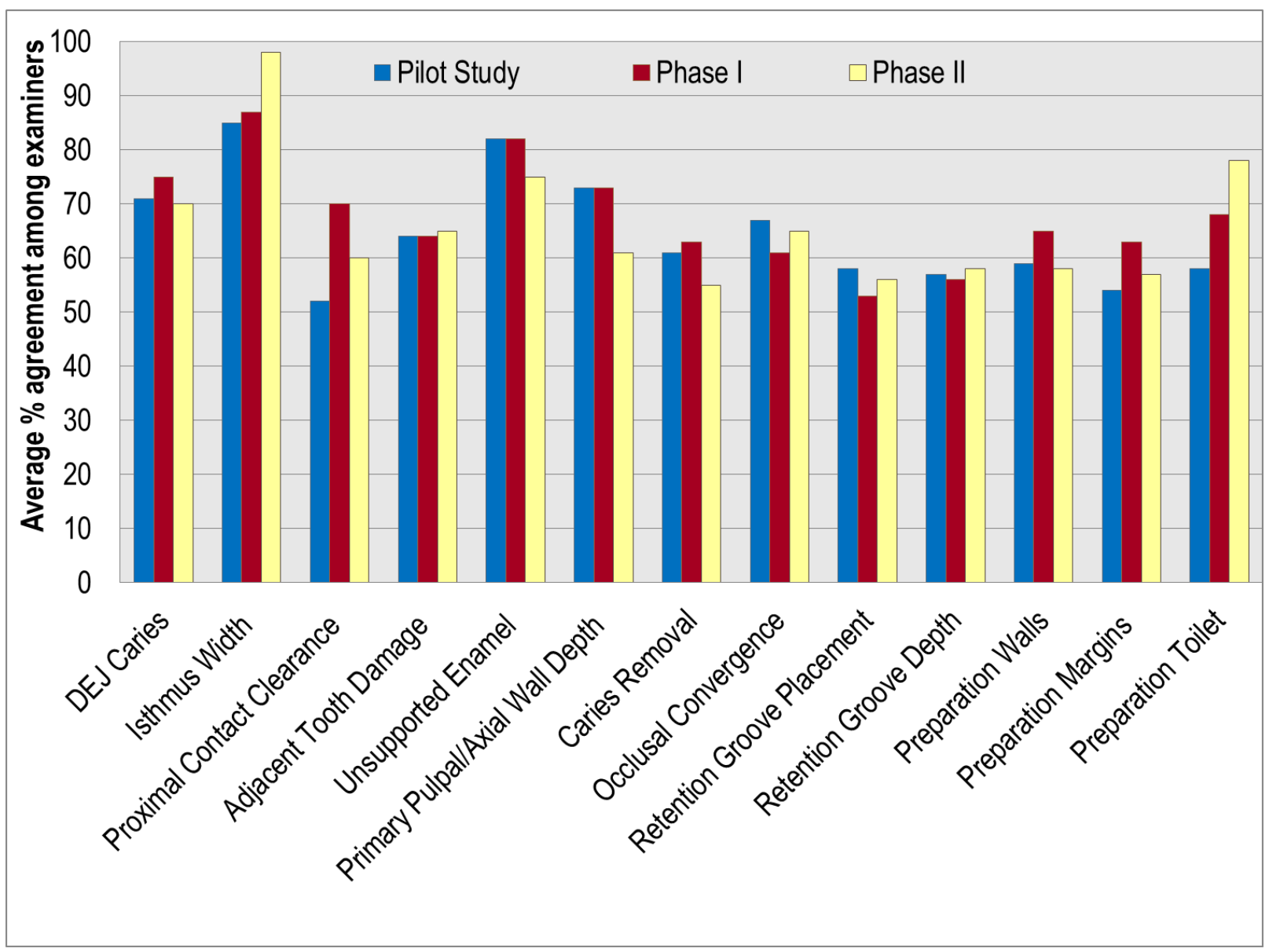

FIGURE 9- Average percentage agreement among examiners after assessment of 13 procedural components of Class II cavity preparations, identified in the post 
TABLE 7 - Average percent agreement (mean +/- sd) and 95\% CI for assessment of components of Class II cavity preparation during Phase II

\begin{tabular}{|l|c|c|c|}
\hline $\begin{array}{c}\text { COMPONENTS OF CLASS II CAVITY } \\
\text { PREPARATION }\end{array}$ & MEAN & STD DEV & $\begin{array}{c}\text { 95\% CI - PHASE II } \\
\text { (LOWER, UPPER) }\end{array}$ \\
\hline DEJ Caries & 68.87 & 20.01 & $(61.11,76.62)$ \\
Isthmus Width & 97.66 & 2.90 & $(96.53,98.78)$ \\
Proximal Contact Clearance & 60.27 & 17.78 & $(53.38,67.17)$ \\
Adjacent Tooth Damage & 65.07 & 15.26 & $(59.15,70.99)$ \\
Enamel Present & 78.24 & 31.19 & $(66.15,90.33)$ \\
Primary Pulpal/Axial Wall & 63.73 & 23.74 & $(54.53,72.94)$ \\
Caries Removal & 55.03 & 28.73 & $(43.88,66.17)$ \\
External Walls & 66.08 & 25.08 & $(56.35,75.80)$ \\
Retentive Groove Placement & 53.24 & 17.36 & $(46.51,59.97)$ \\
Retention Groove Depth & 55.92 & 13.96 & $(50.51,61.33)$ \\
Preparation Walls & 58.04 & 10.60 & $(53.93,62.15)$ \\
Preparation Margins & 55.47 & 13.19 & $(50.36,60.59)$ \\
Preparation Toilet & 80.25 & 15.73 & $(74.15,86.35)$ \\
\hline
\end{tabular}


TABLE 8 - Average percentage intraexaminer agreement for each examiner when comparing the results from Pilot Study to Phase II

\begin{tabular}{|c|c|c|}
\hline $\begin{array}{c}\text { EXAMINERS: PILOT STUDY - } \\
\text { PHASE II }\end{array}$ & $\begin{array}{c}\text { AVERAGE INTRA } \\
\text { EXAMINER AGREEMENT } \\
(\boldsymbol{\%})\end{array}$ & $\begin{array}{c}\text { AVERAGE } \\
\text { KAPPA }\end{array}$ \\
\hline Examiner A Pilot - Phase II & 67 & 0.12 \\
\hline Examiner B Pilot - Phase II & 65 & 0.23 \\
\hline Examiner C Pilot - Phase II & 86 & 0.26 \\
\hline Examiner D Pilot - Phase II & 81 & 0.37 \\
\hline Examiner E Pilot - Phase II & 77 & 0.33 \\
\hline Examiner F Pilot - Phase II & 82 & 0.45 \\
\hline Examiner G Pilot - Phase II & 78 & 0.42 \\
\hline Examiner H Pilot - Phase II & 81 & 0.31 \\
\hline
\end{tabular}


TABLE 9 - Average percentage intraexaminer agreement for each examiner when comparing the results from Phase I to Phase II

\begin{tabular}{|c|c|c|}
\hline EXAMINERS- PHASE I : PHASE II & $\begin{array}{c}\text { AVERAGE INTRA } \\
\text { EXAMINER AGREEMENT } \\
(\boldsymbol{\%})\end{array}$ & $\begin{array}{c}\text { AVERAGE } \\
\text { KAPPA }\end{array}$ \\
\hline Examiner A Phase I - Phase II & 71 & 0.28 \\
\hline Examiner B Phase I - Phase II & 62 & 0.18 \\
\hline Examiner C Phase I - Phase II & 81 & 0.17 \\
\hline Examiner D Phase I - Phase II & 78 & 0.27 \\
\hline Examiner E Phase I - Phase II & 83 & 0.42 \\
\hline Examiner F Phase I - Phase II & 86 & 0.47 \\
\hline Examiner G Phase I - Phase II & 66 & 0.19 \\
\hline Examiner H Phase I - Phase II & 79 & 0.24 \\
\hline
\end{tabular}




\section{Isthmus Width}

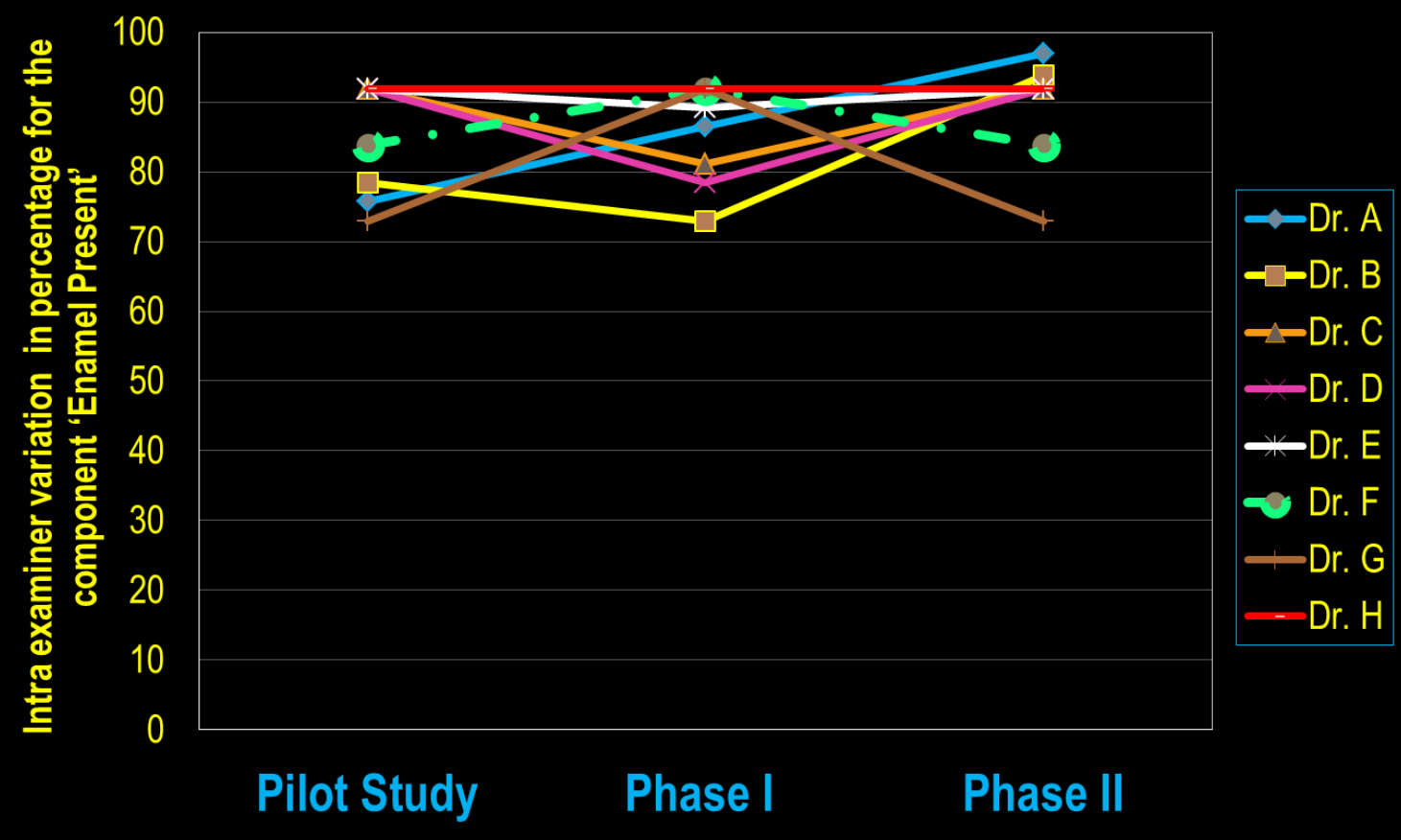

FIGURE 10 - The component 'Isthmus Width' had the lowest intraexaminer variation from Pilot Study: Phase I: Phase II. 


\section{Proximal Contact Clearance}

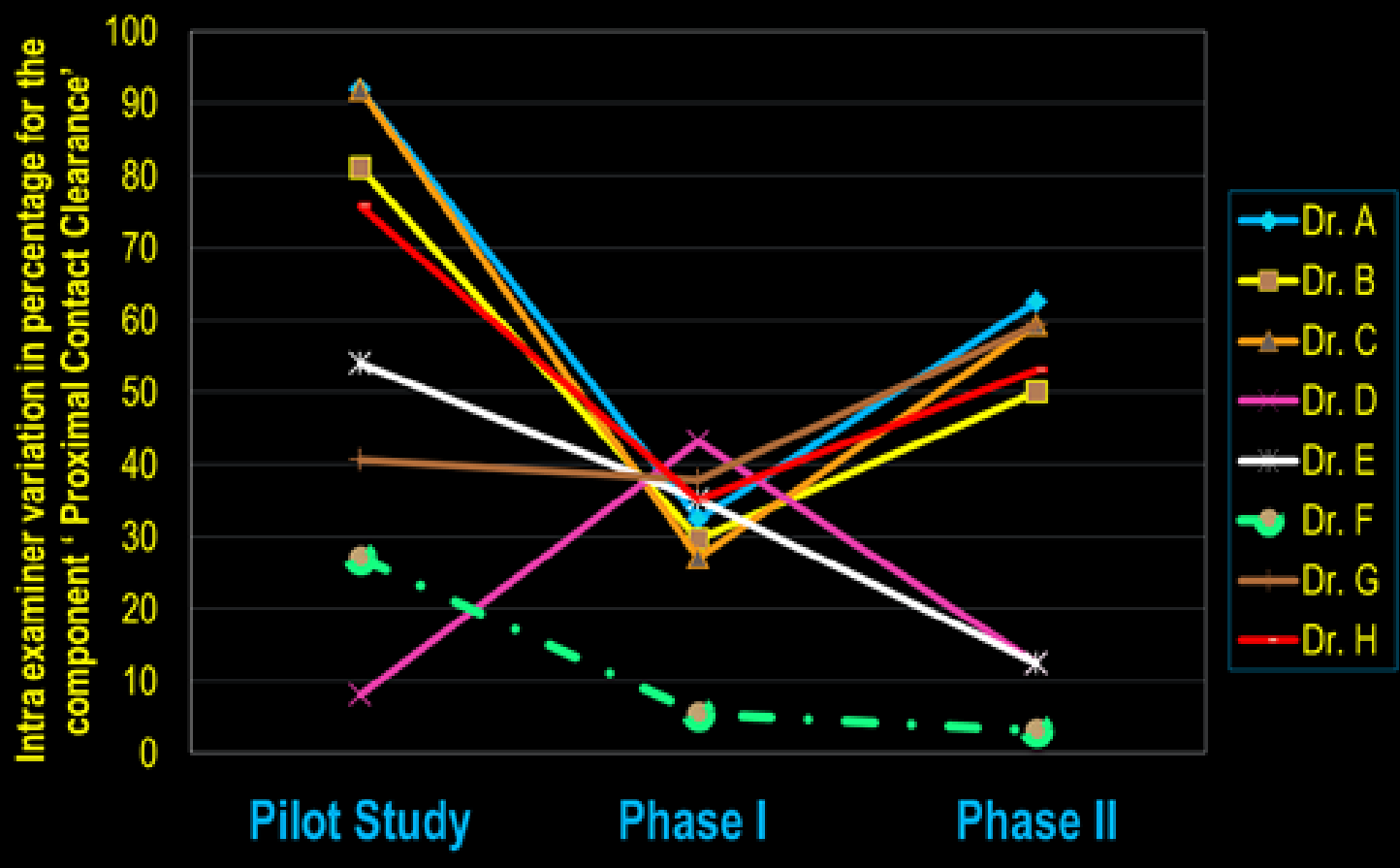

FIGURE 11 - The component 'Proximal Contact Clearance' had the highest intraexaminer variation from Pilot Study: Phase I: Phase II 
TABLE 10 - The level of intraexaminer variation (\%) for all 13 components of Class II cavity preparation for each examiner when comparing the Pilot Study to Phase II

\begin{tabular}{|c|c|c|c|c|c|c|c|c|c|c|c|}
\hline & \multirow{2}{*}{$\begin{array}{l}\text { Components of } \\
\text { Class II cavity } \\
\text { preparation }\end{array}$} & \multicolumn{8}{|c|}{$\begin{array}{c}\text { Degree of intra examiner variation }(\%) \text { between Pilot } \\
\text { study and Phase II for each examiner } \\
\text { Examiners A through } \mathrm{H}\end{array}$} & \multirow[b]{2}{*}{$\begin{array}{c}\text { Mean } \\
(\%)\end{array}$} & \multirow[b]{2}{*}{ Std Dev } \\
\hline & & $\mathbf{A}$ & 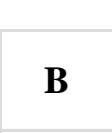 & Exan & niners & A throl & Igh $\mathrm{H}$ & 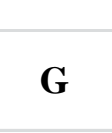 & 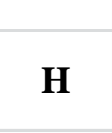 & & \\
\hline \multirow{13}{*}{ 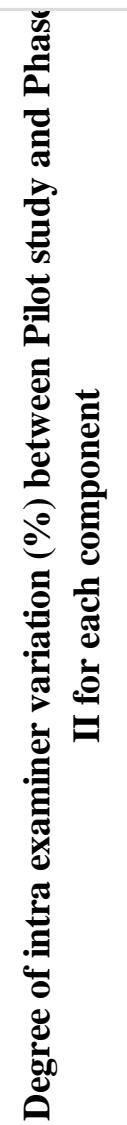 } & DEJ Caries & 20.53 & 29.05 & 0 & 10.1 & 68.58 & 0.25 & 21.37 & 12.67 & 20.3 & 19 \\
\hline & Is thmus Width & 21.2 & 15.37 & 0 & 0 & 0 & 0 & 0 & 0 & 4.6 & 8 \\
\hline & $\begin{array}{l}\text { Proximal Contact } \\
\text { Clearance }\end{array}$ & 29.39 & 31.08 & 32.51 & 4.39 & 41.55 & 23.9 & 18.84 & 22.55 & 25.5 & 10 \\
\hline & $\begin{array}{l}\text { Adjacent Tooth } \\
\text { Damage }\end{array}$ & 28.04 & 5.07 & 4.56 & 3.21 & 4.64 & 3.21 & 14.11 & 7.69 & 8.8 & 8 \\
\hline & Enamel Present & 43.84 & 56.08 & 0 & 0 & 0 & 0 & 0 & 0 & 12.5 & 21 \\
\hline & $\begin{array}{l}\text { Primary } \\
\text { Pulpal/Axial Wall }\end{array}$ & 0 & 33.02 & 2.11 & 15.4 & 10.56 & 1.86 & 5.91 & 14.53 & 10.4 & 10 \\
\hline & Caries Removal & 30.07 & 38.85 & 0 & 23.7 & 19.93 & 0 & 8.7 & 7.26 & 16.1 & 13 \\
\hline & External Walls & 17.23 & 32.6 & 0 & 14.7 & 23.91 & 14.11 & 2.45 & 3.3 & 13.5 & 10 \\
\hline & $\begin{array}{l}\text { Retentive Groove } \\
\text { Placement }\end{array}$ & 16.81 & 16.97 & 5.57 & 7.01 & 7.43 & 14.27 & 40.29 & 46.11 & 19.3 & 14 \\
\hline & $\begin{array}{l}\text { Retention Groove } \\
\text { Depth }\end{array}$ & 6.17 & 13.42 & 38.01 & 8.02 & 13.85 & 1.35 & 46.96 & 59.63 & 23.4 & 19 \\
\hline & Preparation Walls & 15.54 & 9.04 & 17.4 & 19.1 & 1.18 & 14.7 & 13.42 & 11.32 & 12.7 & 5 \\
\hline & $\begin{array}{l}\text { Preparation } \\
\text { Margins }\end{array}$ & 8.69 & 4.3 & 57.94 & 6.93 & 13.77 & 10.98 & 15.54 & 5.07 & 15.4 & 16 \\
\hline & Preparation Toilet & 64.02 & 17.57 & 0 & 29.3 & 21.37 & 16.39 & 26.61 & 0 & 21.9 & 18 \\
\hline
\end{tabular}


TABLE 11- The level of intraexaminer variation (\%) for all 13 components of Class II cavity preparation for each examiner when comparing Phase I to Phase II

\begin{tabular}{|c|c|c|c|c|c|c|c|c|c|c|c|}
\hline & Components of & Degree & of intra & $\begin{array}{l}\text { examin } \\
\text { Phase }\end{array}$ & $\begin{array}{l}\text { II varia } \\
\text { II for e }\end{array}$ & $\begin{array}{l}\text { ion }(\% \\
\text { ch exa }\end{array}$ & $\begin{array}{l}\text { betwe } \\
\text { niner }\end{array}$ & n Pha & I and & & \\
\hline & Class II cavity & & & Exar & iners $A$ & throug & & & & & \\
\hline & & $\mathbf{A}$ & B & $\mathbf{C}$ & D & $\mathbf{E}$ & $\mathbf{F}$ & $\mathbf{G}$ & $\mathbf{H}$ & $\begin{array}{c}\text { Mean } \\
(\%)\end{array}$ & Std. Dev \\
\hline 园 & DEJ Caries & 20.53 & 50.68 & 0 & 20.95 & 6.42 & 5.16 & 8.36 & 4.56 & 14.6 & 14 \\
\hline$\frac{\pi}{2}$ & Isthmus Width & 10.39 & 50.68 & 0.01 & 0 & 0 & 0 & 0 & 0 & 7.6 & 16 \\
\hline כ్ & $\begin{array}{l}\text { Proximal Contact } \\
\text { Clearance }\end{array}$ & 30.07 & 50.68 & 32.35 & 30.74 & 22.64 & 2.28 & 21.54 & 17.99 & 26.0 & 12 \\
\hline 离 & $\begin{array}{l}\text { Adjacent Tooth } \\
\text { Damage }\end{array}$ & 25.34 & 50.68 & 4.56 & 8.61 & 3.47 & 7.6 & 19.52 & 7.69 & 15.9 & 14 \\
\hline $\mathbb{E}_{0}^{\bar{N}}$ & Enamel Present & 51.95 & 50.68 & 0 & 0 & 0 & 0 & 0 & 0 & 12.8 & 21 \\
\hline $\begin{array}{ll}\frac{\pi}{0} \\
0 \\
0\end{array}$ & $\begin{array}{l}\text { Primary } \\
\text { Pulpal/Axial Wall }\end{array}$ & 0 & 50.68 & 41.14 & 31.59 & 8.36 & 1.86 & 19.43 & 9.12 & 20.3 & 17 \\
\hline పี & Caries Removal & 11.15 & 50.68 & 0 & 18.24 & 6.42 & 0 & 0.6 & 4.56 & 11.5 & 15 \\
\hline 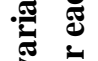 & External Walls & 1.01 & 50.68 & 0 & 11.99 & 4.99 & 22.22 & 64.62 & 16.81 & 21.5 & 21 \\
\hline 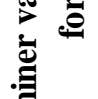 & $\begin{array}{l}\text { Retentive } \\
\text { Groove }\end{array}$ & 6 & 50.68 & 8.28 & 20.02 & 26.35 & 0.76 & 53.81 & 10.98 & 22.1 & 18 \\
\hline 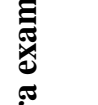 & $\begin{array}{l}\text { Retention } \\
\text { Groove Depth } \\
\text { rreuarauon }\end{array}$ & 0.77 & 50.68 & 8.28 & 21.71 & 11.15 & 1.35 & 60.47 & 46.11 & 25.1 & 21 \\
\hline . & Walls & 34.46 & 50.68 & 4.22 & 7.94 & 15.03 & 22.8 & 32.52 & 37.33 & 25.6 & 14 \\
\hline 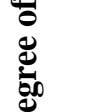 & $\begin{array}{l}\text { Preparation } \\
\text { Margins } \\
\text { Preparation }\end{array}$ & 22.21 & 50.68 & 22.8 & 1.18 & 13.26 & 5.57 & 58.78 & 11.15 & 23.2 & 18 \\
\hline & Toilet & 34.29 & 50.68 & 0 & 13.1 & 29.48 & 10.98 & 29.31 & 0 & 21.0 & 16 \\
\hline
\end{tabular}




\section{REFERENCES}

1. Haj-Ali R, Feil P. Rater reliability: short- and long-term effects of calibration training. Journal of dental education. Apr 2006;70(4):428-433.

2. Sharaf AA, AbdelAziz AM, El Meligy OA. Intra- and inter-examiner variability in evaluating preclinical pediatric dentistry operative procedures. Journal of dental education. Apr 2007;71(4):540-544.

3. Dhuru VB, Rypel TS, Johnston WM. Criterion-oriented grading system for preclinical operative dentistry laboratory course. Journal of dental education. Sep 1978;42(9):528531.

4. Brown G, Manogue M, Martin M. The validity and reliability of an OSCE in dentistry. European journal of dental education : official journal of the Association for Dental Education in Europe. Aug 1999;3(3):117-125.

5. Houpt MI, Kress G. Accuracy of measurement of clinical performance in dentistry. Journal of dental education. Jul 1973;37(7):34-46.

6. Houpt MI, Kress G. Evaluation training: training raters to evaluate clinical performance. Quintessence international, dental digest. Nov 1979;10(11):67-76.

7. Hinkelman KW, Long NK. Method for decreasing subjective evaluation in preclinical restorative dentistry. Journal of dental education. Sep 1973;37(9):13-18.

8. Jenkins SM, Dummer PM, Gilmour AS, Edmunds DH, Hicks R, Ash P. Evaluating undergraduate preclinical operative skill; use of a glance and grade marking system. Journal of dentistry. Nov 1998;26(8):679-684.

9. Lilley JD, ten Bruggen Cate HJ, Holloway PJ, Holt JK, Start KB. Reliability of practical tests in operative dentistry. British dental journal. Sep 3 1968;125(5):194-197.

10. Theodore M. Roberson HOH, Edward J. Swift, Jr. Sturdevant's Art and Science of Operative Dentistry 2006.

11. Scruggs RR, Daniel SJ, Larkin A, Stoltz RF. Effects of specific criteria and calibration on examiner reliability. Journal of dental hygiene : JDH / American Dental Hygienists' Association. Mar-Apr 1989;63(3):125-129.

12. Viera AJ, Garrett JM. Understanding interobserver agreement: the kappa statistic. Family medicine. May 2005;37(5):360-363.

13. Dimitrijevic T, Kahler B, Evans G, Collins M, Moule A. Depth and distance perception of dentists and dental students. Operative dentistry. Sep-Oct 2011;36(5):467-477. 
14. Moore DL. Current teaching of proximal retention grooves for Class II amalgam preparations. Journal of dental education. Feb 1992;56(2):131-134.

15. Mackenzie RS. Defining clinical competence in terms of quality, quantity, and need for performance criteria. Journal of dental education. Sep 1973;37(9):37-44. 